\title{
The $[5+5]$ route to the phenanthrene skeleton
}

\author{
James W. Herndon* and Bishnu Dhakal \\ Department of Chemistry and Biochemistry, New Mexico State University, \\ Las Cruces, New Mexico, 88003, USA \\ E-mail: jherndon@nmsu.edu
}

\begin{abstract}
Dedicated to the memory of Prof. Alan R. Katritzky, a pioneer in heterocyclic chemistry and open access publication
\end{abstract}

DOI: $\underline{\text { http://dx.doi.org/10.3998/ark.5550190.p009.611 }}$

\begin{abstract}
This account describes the historical development of the coupling of $\gamma, \delta$-unsaturated Fischer carbene complexes and $o$-alkynylbenzaldehydes, which directly affords hydrophenanthrene ring systems in a process where each reactant contributes five carbons to the newly-formed bicyclo[4.4.0]decane ring system. The process has been termed net [5+5] cycloaddition. Use of the reaction to produce various medicinally important natural products and/or their parent ring systems is discussed.
\end{abstract}

Keywords: Fischer carbene complexes, alkynes, phenanthrenes, Diels-Alder reactions, isobenzofurans, cycloaddition, annulation

\section{Table of Contents}

1. Introduction

1.1 Importance of phenanthrenes

1.2 Coupling of Fischer carbene complexes with complex enyne systems

2. Scope and Limit of Formal [5+5] Cycloaddition

2.1 Isobenzofuran generation

2.2 Establishing the [5+5] cycloaddition reaction

2.3 Steroid ring synthesis using [5+5] cycloaddition

2.4 Relative asymmetric induction in $[5+5]$ cycloaddition

2.5 [5+5] cycloadditions using highly oxygenated benzenes for phenanthrene alkaloid syntheses

2.6 [5+5] Cycloaddition reactions in hydroxylic solvents

2.7 Syntheses of phenalene systems using [5+5] cycloaddition

2.8 Approaches to aporphine alkaloid ring systems 
2.9 Use of amide carbonyl groups in the [5+5] cycloaddition

2.10 Use of heteroaromatic systems in the [5+5] cycloaddition

2.11 Use of triply bonded systems in the [5+5] cycloaddition

2.12 [5+6] cycloaddition approach to benzocycloheptanes

2.13 Other studies of [5+5] cycloaddition

3. Conclusions

4. Acknowledgements

5. References

Author Biographies

\section{Introduction}

In the following account we detail our development of the coupling of Fischer carbene complexes featuring $\gamma, \delta$-unsaturation with $o$-alkynylbenzaldehydes (and ketone analogs), which affords the phenanthrene skeleton through a complex series of reactions. We have termed this reaction "net $[5+5]$ cycloaddition" to reflect the carbons that are combined together to make both rings of a new bicyclo[4.4.0]decane system in a single reaction event, using precursor compounds where neither of the rings was present in the reactants. We acknowledge that there are many organic chemists who feel that the term cycloaddition reaction is reserved for pericyclic reactions, however this process is a formal cycloaddition ${ }^{1}$ in that new rings are formed in an overall intermolecular process.

The basic presentation begins with a chronological progression starting with early efforts to develop the key reaction process from on-going research projects, followed by efforts to gear the key reaction to various important target molecules and efforts to incorporate specific structural variables into the reaction. In each case we present only a few examples of the key reaction. For a more detailed description the reader should consult the original papers referenced.

The chemistry contained in this article was accomplished by a very talented and dedicated group of graduate students, postdoctoral associates, and colleagues who made many original contributions critical to the overall successes. These co-workers are listed in order of their work's placement within the manuscript, and include Anthony Hayford, Haixia Wang, Delu Jiang, Binay K. Ghorai, Suneetha Menon, Dennis L. Johnson, Dilip Sinha-Mahapatra, Alejandro CamachoDavila, Waylon (Weijiang) Ying, Lalith S. R. Gamage, Rongti Li, Lei Zhang, Rajesh K. Patti, Zhiping Wang, Yanshi Zhang, Jianwei Zhang, Kris Waynant, Shaofeng Duan, and Yumei Luo.

\subsection{Importance of phenanthrenes}

The phenanthrene carbon skeleton system appears as a structural component of many pharmaceutically-important compounds (see Figure 1), including steroids (e.g. estrone), ${ }^{2}$ morphine alkaloids (e.g. Vicodin $)^{3}$ aporphines (e.g. apomorphine), ${ }^{4}$ phenanthroindolizidine (e.g. antofine) and phenanthroquinolizidine (e.g. cryptopleurine) alkaloids, ${ }^{5}$ and various resveratrole-derived compounds (e.g. laetevirenol A) ${ }^{6}$ Phenanthrenes are a basic subunit of numerous polycyclic aromatics, which have found extensive use in molecular electronics and the design of novel 
photoactive molecules. Smaller polycyclic aromatic systems are combustion byproducts frequently found as ubiquitous environmental pollutants, and preparation of derivative compounds is often critical to understanding their modes of action. ${ }^{7}$
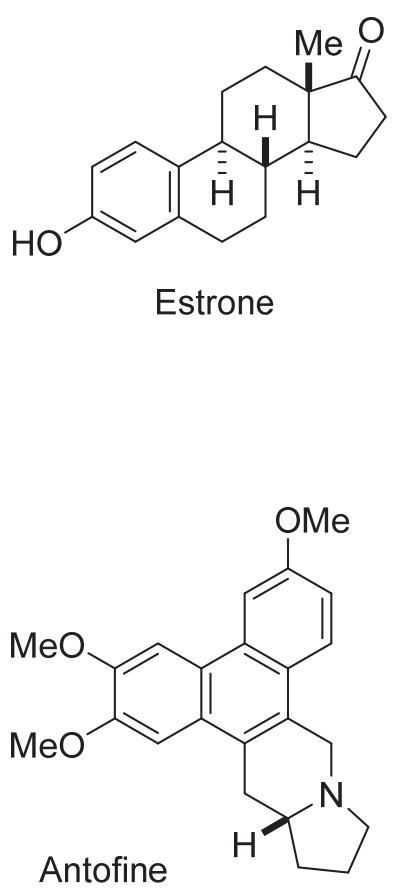

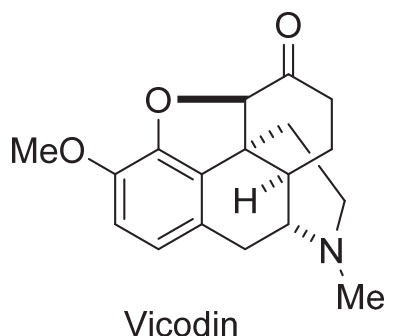

Vicodin

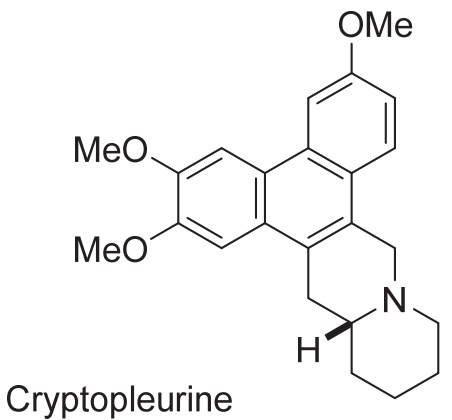<smiles>CN1CCc2cccc3c2[C@H]1Cc1ccc(O)c(O)c1-3</smiles>

Apomorphine<smiles>Oc1ccc([C@@H]2c3c(O)cc(O)c4c3c(cc3ccc(O)cc34)[C@@H]2c2cc(O)cc(O)c2)cc1</smiles>

Figure 1. Medicinally-important compounds containing a phenanthrene skeleton.

Preparation of hydrophenanthrenes and functional analogs is a continuing area of interest, and chemical processes that result in the efficient and versatile construction of this ring system will be highly beneficial to these efforts. Common methods for the synthesis of this ring system include adding a benzene ring to a naphthalene ring system $^{8-10}$ and formation of an additional carbon-carbon bond from a cis stilbene system. ${ }^{11}$ Several years ago we began to look at a novel design protocol for phenanthrene synthesis (see Scheme 1) where two five-carbon donors, a $\gamma, \delta$-unsaturated carbene complex (B) and an $o$-alkynylbenzoyl system (A) couple in a novel transition metal mediated formal [5+5] cycloaddition process. This account will outline the development of this process, and its successful and unsuccessful applications to organic synthesis. The reaction entails a very unique and convergent construction of two fused six-membered rings (i.e. a hydronaphthalene ring system) where each of the two reacting components contributes at least two carbons to each of the sixmembered rings of the newly-formed hydronaphthalene system. 


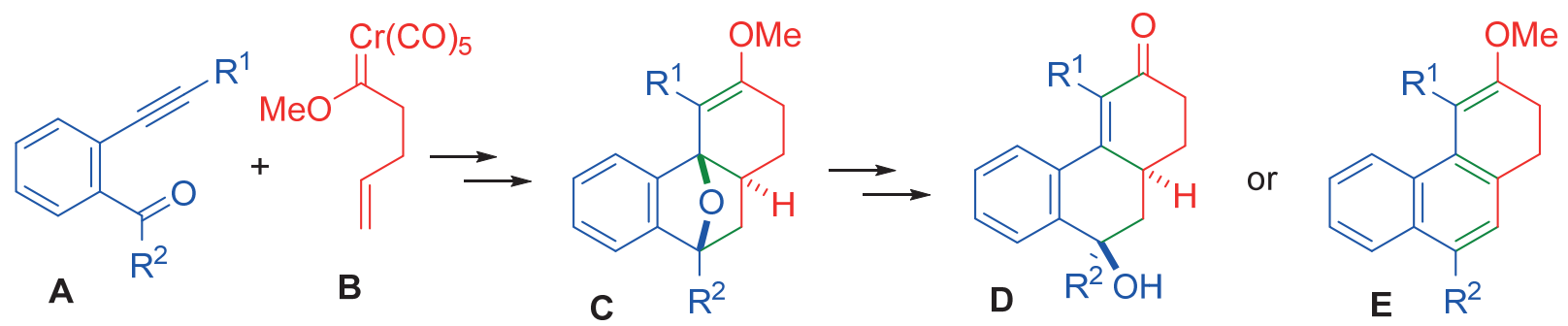

Scheme 1. The [5+5] cycloaddition approach to the phenanthrene skeleton.

\subsection{Coupling of Fischer carbene complexes with complex enyne systems}

The development of the [5+5] cycloaddition process grew from a project pursued at the University of Maryland involving the coupling of conjugated cis dienynes (e.g. 2, Scheme 2) and simple carbene complexes (e.g. 3) as surrogates for the coupling of simple alkynes with either $\alpha, \beta$ unsaturated chromium carbene complexes ${ }^{12}$ or cyclopropylcarbene complexes ${ }^{13}$ in various cycloaddition reactions. ${ }^{14}$ While looking intensely at this synthetic scheme for conjugated dienyne preparation a novel idea emerged. Making the requisite dienyne in all cases involved a Wittig reaction as the final step. However in the Wittig reaction precursor (e.g. 1) a $\pi$-bond was already in the correct orientation for a potentially interesting cyclization reaction involving an intermediate vinylcarbene complex (7). The coupling reaction of carbene complex $\mathbf{3}$ with enyne aldehyde precursor $\mathbf{1}$ afforded the furan derivative $\mathbf{8}$ as the only identifiable product in $>60 \%$

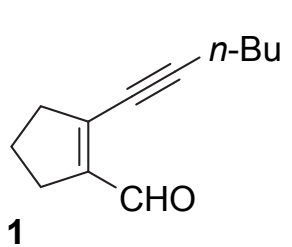

1

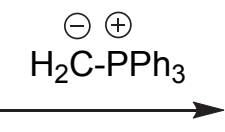<smiles>COC(=O)C(C)=C(C)OC</smiles><smiles>CCCC1CCCC1=C(C(=O)C=O)C(C(=O)[O-])=C(C)OC</smiles>

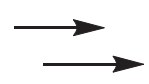

7

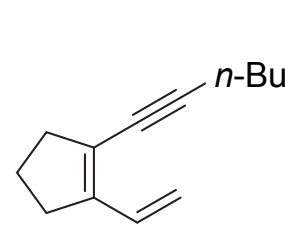

2
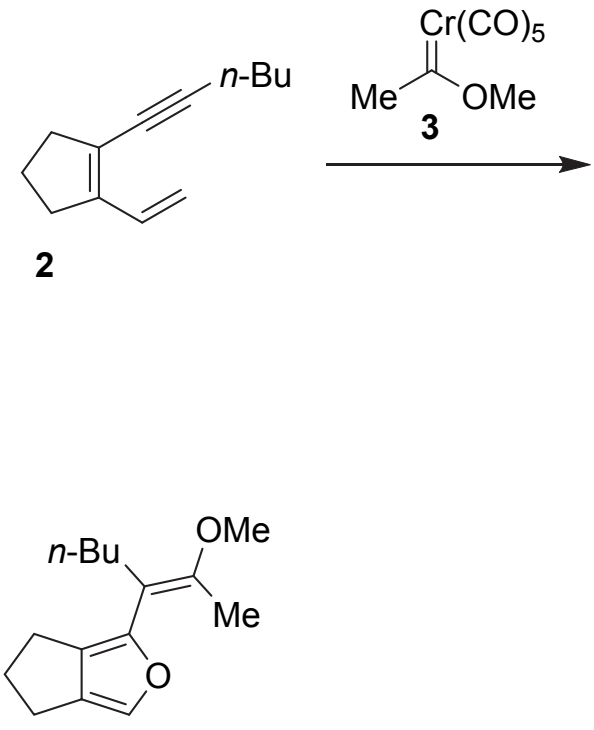

8<smiles>C=CC1=C(C(C(=O)[O-])=C(C)C)C(OC)=C(C(=O)OC)C1</smiles>

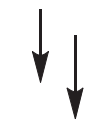<smiles>CCCC/C(=C(/C)OC)c1c(O)ccc2c1CCC2</smiles>

5

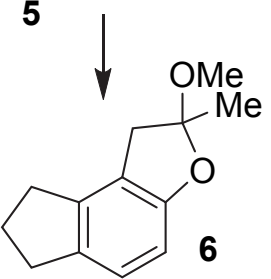

Scheme 2. Conjugated dienynes as surrogates for $\alpha, \beta$-unsaturated Fischer carbene complexes. 
yield on the very first attempt at this reaction. ${ }^{15}$ After publishing this finding in several systems and contemplating the synthetic potential of this reaction, we realized that a potentially very useful extension of this reaction would entail making the central alkene group part of a benzene ring. If an identical reaction pathway ensues, an isobenzofuran system would then be produced. The synthetic utility of the isobenzofuran ring system as a source of activated dienes for cycloaddition reactions is well documented. ${ }^{16}$

\section{Scope and Limit of Formal [5+5] Cycloaddition}

\subsection{Isobenzofuran generation}

Isobenzofuran investigations began with the move of the research group to New Mexico State University in 1997. In this initial investigation we showed that alkylidenephthalans (11, Scheme 3) are produced when no external dienophile was present and hydronaphthalene systems $($ e.g. 12, 16) were produced in the presence of a dienophile additive. ${ }^{17}$ The structure of these reaction products suggest that an isobenzofuran system (10) was successfully generated. In the absence of the dienophile the isobenzofuran intermediate can engage in a 1,7-hydrogen shift process to afford the alkylidenephthalan after enol ether hydrolysis. When a dienophile is present, the isobenzofuran Diels-Alder adduct is produced. Competing processes are direct reaction of the carbene complex with the dienophile, which accounts for the cyclopropanation (13) and polymeric byproducts, depending upon whether the dienophile is an alkene or an alkyne. The reaction was less successful with the alkyne dienophile dimethyl acetylenedicarboxylate (DMAD), which is likely to be due

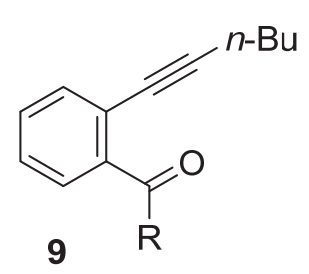

$\mathrm{R}=\mathrm{H}, \mathrm{Me}$, or $\mathrm{Ph}$

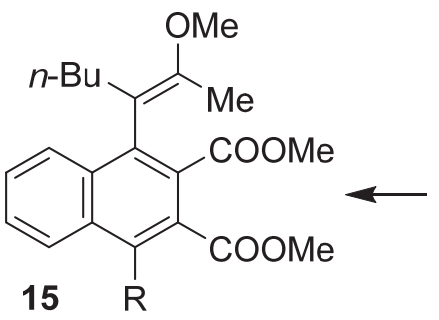

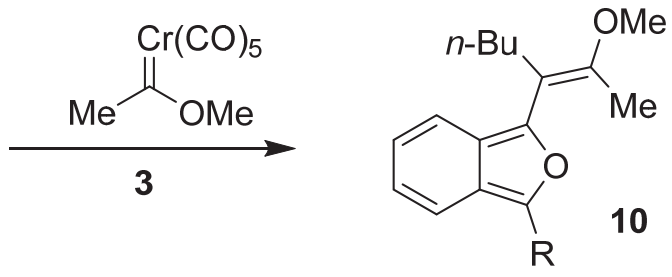

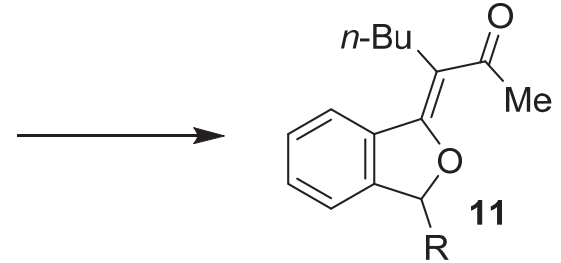

$\mathrm{R}$

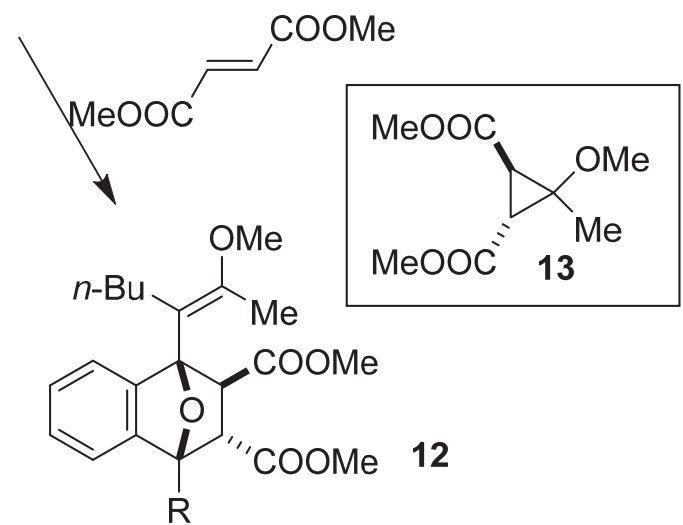

Scheme 3. Two and three-component coupling processes involving isobenzofuran intermediates. 
to multiple alkyne entities available for reaction with the carbene complex. The three component coupling was most efficient using the phenyl ketone derivative in a sequential addition reaction due to the enhanced stability of the sterically hindered isobenzofuran intermediate. Successful threecomponent coupling was later realized using hydrazones in place of carbonyl compounds, and the success of this process was attributed to the enhanced stability of isoindoles relative to isobenzofurans. $^{18}$

\subsection{Establishing the $[5+5]$ cycloaddition reaction}

After establishing that isobenzofuran intermediates are indeed generated in the coupling of $O$ alkynylbenzaldehyde derivatives and Fischer carbene complexes, the next step was the successful implementation of the major theme reaction of this account, the [5+5] route to phenanthrenoid systems (Scheme 4). The idea takes advantage of the fact that carbene-alkyne insertion affords a vinylcarbene complex intermediate (18) as predominantly the $E$-enol ether alkene system ${ }^{19}(E / Z$ assignment based on a terminal alkyne starting material), thus if the carbene complex carries a suitably placed alkene group then an intramolecular Diels-Alder reaction can ensue.
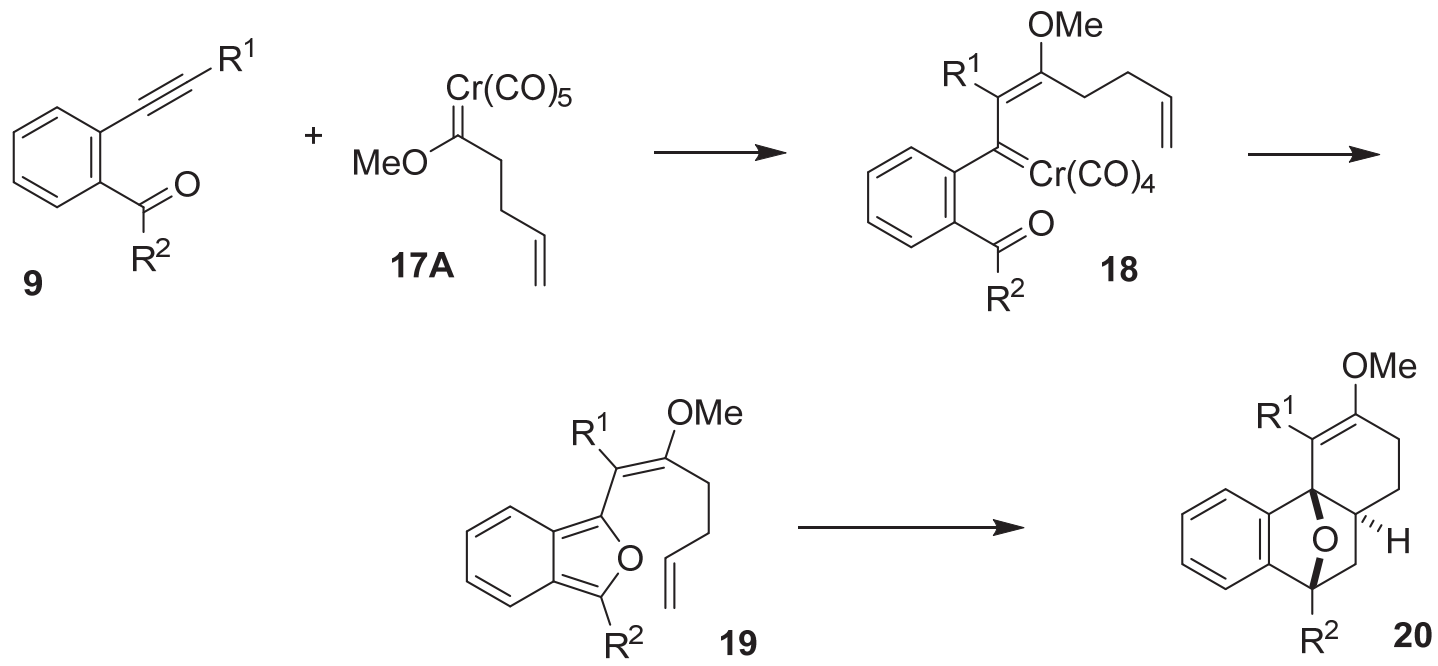

Scheme 4. Basic idea behind the net [5+5] cycloaddition reaction.

An additional feature of this tandem reaction is that the alkene is not activated for the

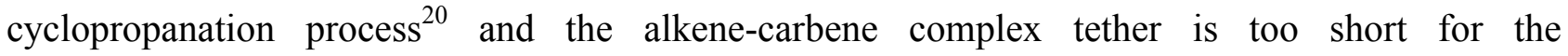
intramolecular cyclopropanation process. Related Diels-Alder reactions are reported to be stereoselective and proceed with exo stereoselectivity. ${ }^{21}$ This process also features a potentially very high degree of molecular diversity due to the synthetic availability of each of the coupling partners (see Scheme 5). A variety of $\gamma, \delta$-carbene complexes can arise through allylation of carbene complexes having $\alpha$-hydrogens. ${ }^{22}$ These derivatives are also accessible from $\gamma, \delta$-unsaturated acid chlorides (themselves the products of Claisen rearrangements) through the Hegedus $^{23} /$ Semmelhack $^{24}$ protocol, from 5-halo-1-pentene derivatives through lithiation followed by the Fischer synthesis, or from Michael addition of vinyl anion equivalents to $\alpha, \beta$-unsaturated 
carbene complexes. ${ }^{25}$ The $o$-alkynylbenzoyl coupling partners arise from 2-halobenzaldehydes or salicaldehyde derivatives through Sonogashira couplings, or through acylation of $o$-alkynylphenyl halide derivatives.
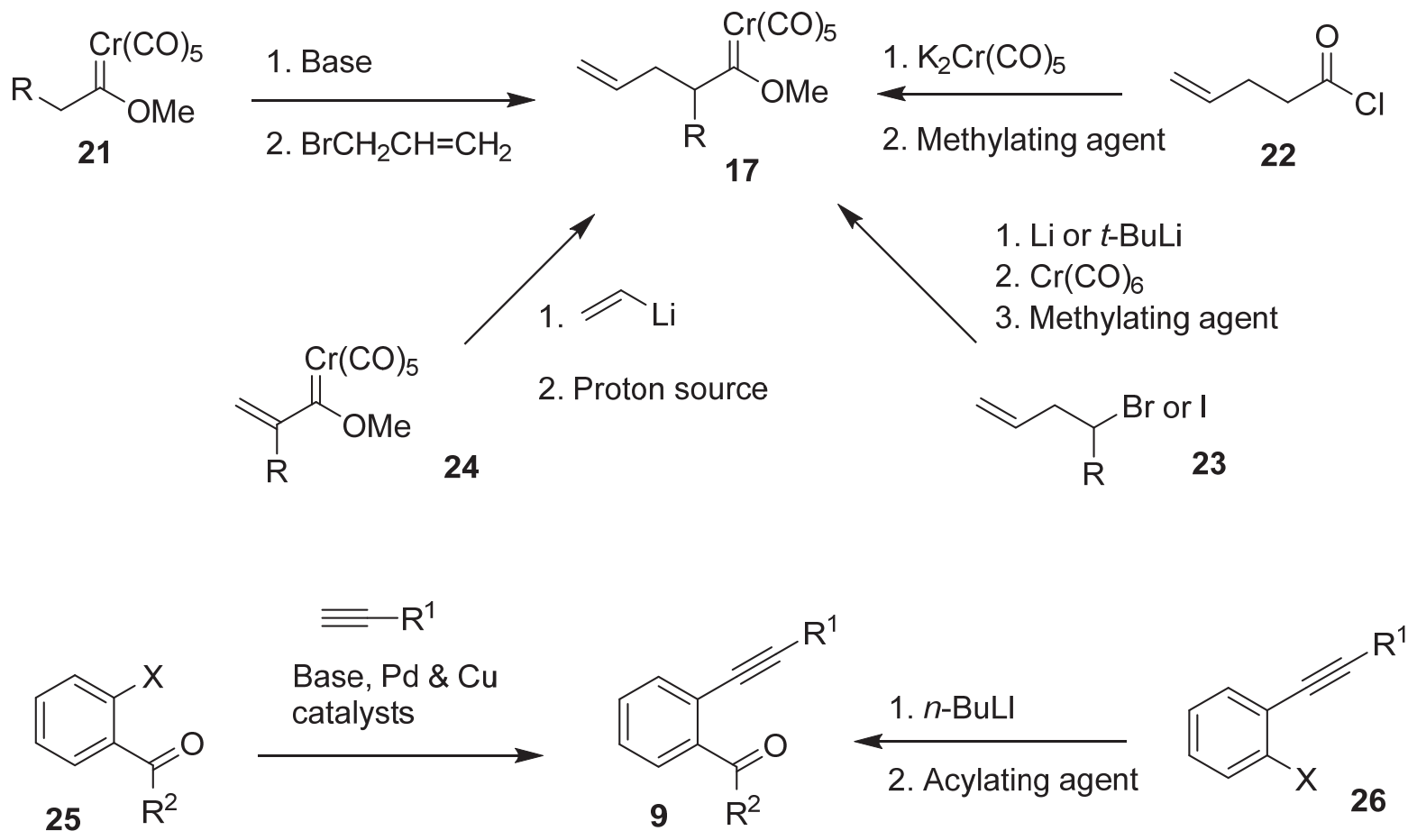

Scheme 5. General synthetic routes to [5+5] cycloaddition partners.

The initial assessment of the [5+5] cycloaddition process involved a simpler two-component system where the alkene group was tethered through the carbonyl group (27, Scheme 6) and the coupling process uses a simple carbene complex (3). The crude reaction mixture was somewhat complex, featuring a variety of products derived from opening of the oxanorbornene intermediate, including enol ethers, ketones, arene complexes, and aromatized products. Ultimately, to assess the efficiency of the key steps, the crude reaction mixture was converted to the naphthalene systems by refluxing for a longer time period $(>24 \mathrm{~h}$ ) and treatment of the crude reaction mixtures with $p$ toluenesulfonic acid. The naphthalene products depicted were the only product observed under these conditions. The naphthalene-forming reaction proceeded in moderate yield for the threecarbon tethered system and higher yield for the four-carbon tethered system. In later developments (see ahead) it was noted that a simple additive (water) allowed for the clean isolation of ketonecontaining cycloadducts. 

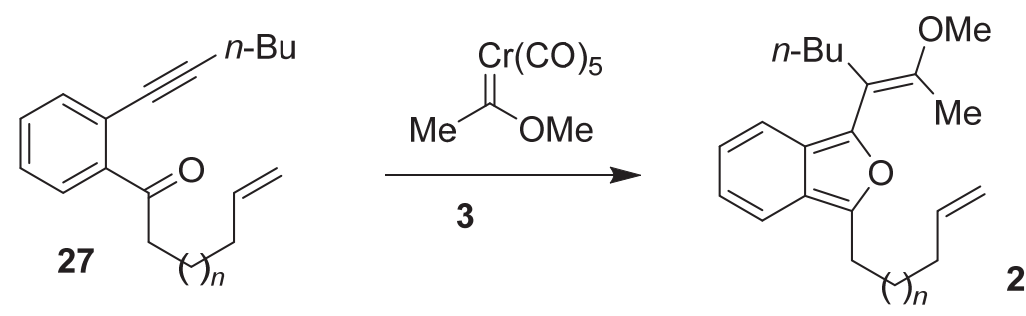

28

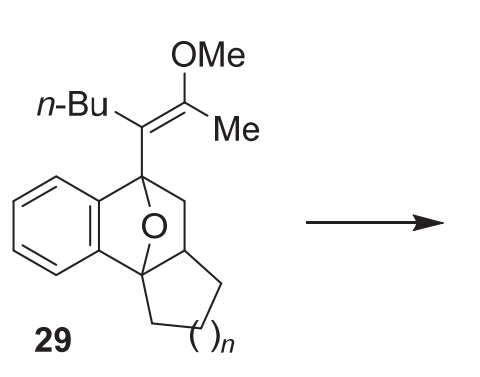

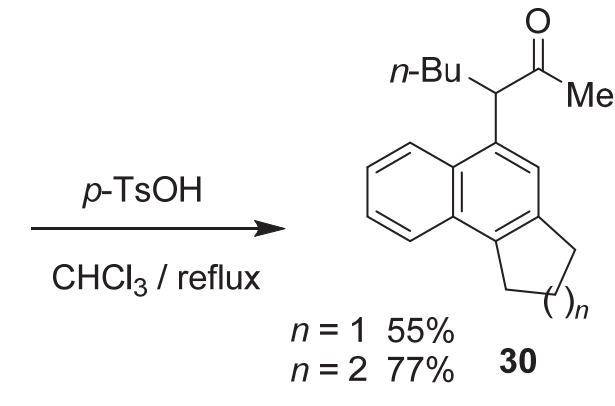

Scheme 6. Capture of isobenzofuran intermediates in systems featuring an alkene-ketone tether.

The initial investigation of the truly two-component [5+5] coupling entailed the coupling of $\gamma, \delta$-unsaturated carbene complex 17A and butylated enyne system 9C (Scheme 7). Early investigations were hindered by limited control of monoallylation versus diallylation in the synthesis of the carbene complexes. The initial reactions were examined using excess complex contaminated with up to $20 \%$ of the diallylated complex in anticipation that the sterically less hindered major monoallylated carbene complex would be the more reactive one, which turned out to be the case. The initial studies were conducted using the phenyl ketones since these systems exhibited long-lived isobenzofuran moieties. The reaction as initially investigated yielded a mixture of complexed and uncomplexed products as well as various amounts of elimination and hydrolysis products. In order to gauge the efficacy of the key steps, the reaction was subjected to longer reaction times and the crude reaction mixtures were treated with $p$-toluenesulfonic acid prior to isolation. Under these conditions, the reaction was surprisingly efficient, leading to the hydrophenanthrenone derivative $\mathbf{3 1}$ in good yield. Examination of the crude reaction mixture revealed virtually no absorptions between 5-6 ppm in the proton NMR spectrum, showing that there was tremendous efficiency in the Diels-Alder step of the reaction. The reactions were also examined using the $\gamma$-methylated $\gamma, \delta$-unsaturated carbene complex $17 \mathbf{B}$, which could be obtained more cleanly due to fewer problems with overallylations using methallyl bromide. The reaction employing the aldehyde afforded the alcohol $\mathbf{3 2}$ as a single diastereomer assigned as the depicted structure due to the exo nature of the Diels-Alder step. Acid treatment of the alkyne-ketone derivatives ultimately resulted in alkene systems $\mathbf{( 3 3 )}$ due to a facile dehydration of the tertiary alcohol systems employed. 


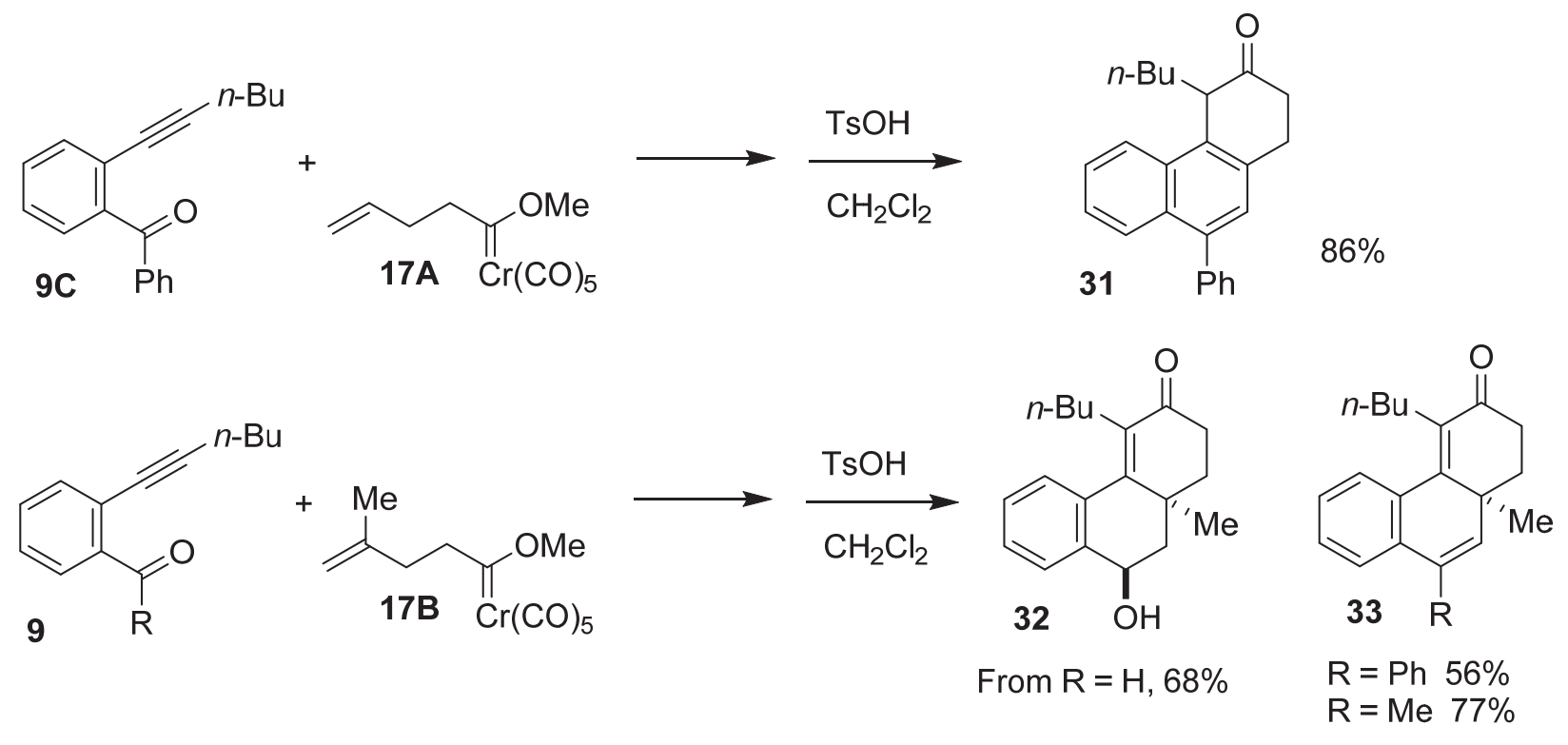

Scheme 7. Initial examination of the two-component [5+5] cycloadditions.

Efforts to isolate oxygen-bridged intermediates were not successful. Purification of the crude reaction mixtures with triethylamine-treated silica gel resulted in the isolation of compounds tentatively identified as enol ethers as well as the ketone products. Formation of these types of products directly from the reaction is due to the hydrolytic instability of the oxygen bridge (Scheme 8). Due to a combination of angle strain inherent in a norbornene system and the substantial carbocation stabilizing ability of the enol ether group the lability of this ring system is no surprise. Although the reaction was performed under anhydrous conditions one cannot rule out silicon atoms in the glass or chromium by-products from the reaction serving as Lewis acids.<smiles>[R]c1cc2c(c3ccccc13)C(CC(C)C)C(=O)CC2</smiles>

Scheme 8. Hydrolytic instability of the oxanorbornene intermediates. 


\subsection{Steroid ring synthesis using [5+5] cycloaddition}

From the onset, we imagined that the most obvious application of this reaction would be for the synthesis of steroids. The steroid synthesis would merely require the preparation of a $\gamma, \delta$ unsaturated carbene complex templated through a cyclopentane ring system (36, Scheme 9). Several of these compounds were prepared and successfully employed in the [5+5] cycloaddition process to afford compounds that feature the steroid ring system $(\mathbf{3 7}) \cdot{ }^{26}$ The process proceeded with complete control of the newly formed stereocenters of the $B$ ring, however in the parent system where $R^{1}=H$ and $n=1$, epimerization at the $\alpha$-carbonyl stereocenter (asterisked) led to a mixture of cis and trans hydrindanes favoring the cis hydrindane system. The primary difficulty with this reaction as a general steroid synthesis is the often tedious synthetic routes required for the Fischer carbene complex component of these reactions. Although one derivative (36D) was somewhat easy to prepare via a mere Michael addition process to the cyclopentenyl carbene complex (38), in most of the cases a somewhat tedious synthetic route beginning with $\gamma$-butyrolactone (39) was required. The six-membered ring carbene complex starting material was an already known compound. ${ }^{23}$<smiles>CC#Cc1ccccc1C=O</smiles>

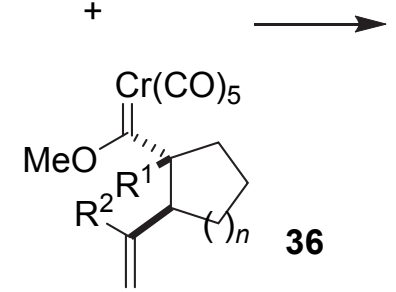<smiles>COC(=O)C(OC)=C1CCCCC1</smiles>

38

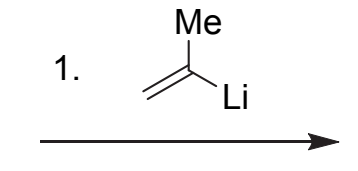

2. $\mathrm{CH}_{3} \mathrm{COOH}$

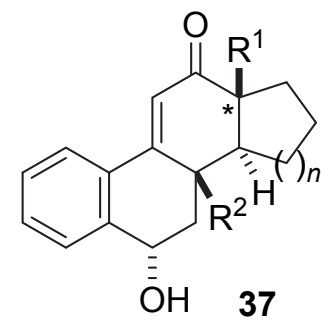<smiles>C=C(C)[C@H]1CCC[C@@H]1C(C(=O)OC)=C(C)[O-]</smiles>

$$
\begin{array}{llll}
\underline{\mathrm{R}}^{1} & \underline{\mathrm{R}}^{2} & \underline{n} & \text { Yield } \\
\mathrm{H} & \mathrm{H} & 1 & 66 \% * \\
\mathrm{Me} & \mathrm{H} & 1 & 49 \% \\
\mathrm{H} & \mathrm{H} & 2 & 75 \% \\
\mathrm{H} & \mathrm{Me} & 1 & 60 \% \\
\text { *In this case the product } \\
\multicolumn{4}{l}{\text { was obtained as a } 60: 40}
\end{array}
$$
cis:trans hydrindane mixture.<smiles>O=C1CCCC1</smiles>

39

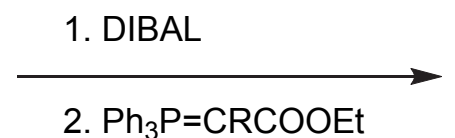

3. $\mathrm{TsCl} / \mathrm{py}$

4. Nal

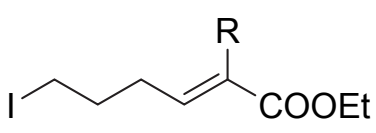

40

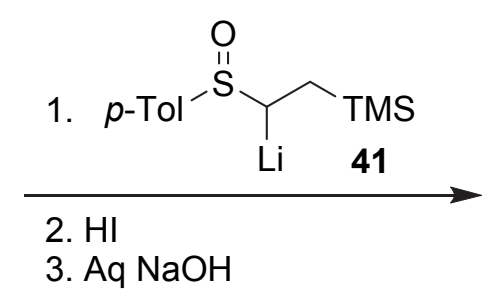

2. $\mathrm{H}$

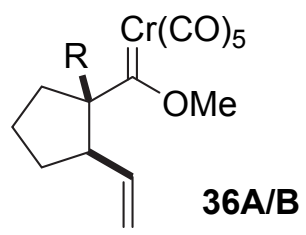

Scheme 9. The $[5+5]$ route to steroid derivatives. 


\subsection{Relative asymmetric induction in [5+5] cycloaddition}

On account of the results described above, the reaction was examined in the presence of other starting materials that contained a preexisting stereocenter and the relative asymmetric induction processes examined (Scheme 10). ${ }^{27}$ The carbene complexes featuring a single $\beta$-stereocenter in the tether $(\mathbf{1 7 C} / \mathbf{D})$ led to a single diastereomer assigned as isomer $\mathbf{3 2}$, which arises from an exo selective Diels-Alder reaction where the substituent resides in a pseudoequatorial position in the Diels-Alder transition state. ${ }^{28}$ The direction of stereocontrol was opposite if the alkene was

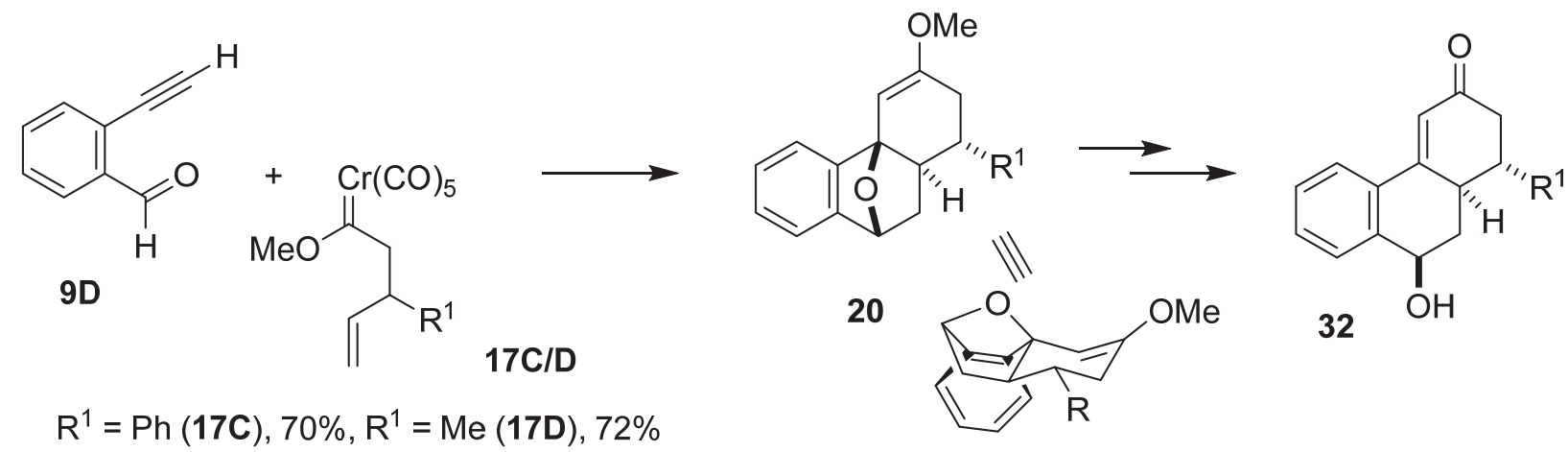<smiles>[R]C1=C([R])C([R])(CC(OC)=C(C(=O)[O-])C(=O)O[Na])CC([R7])([R])C1</smiles>

43

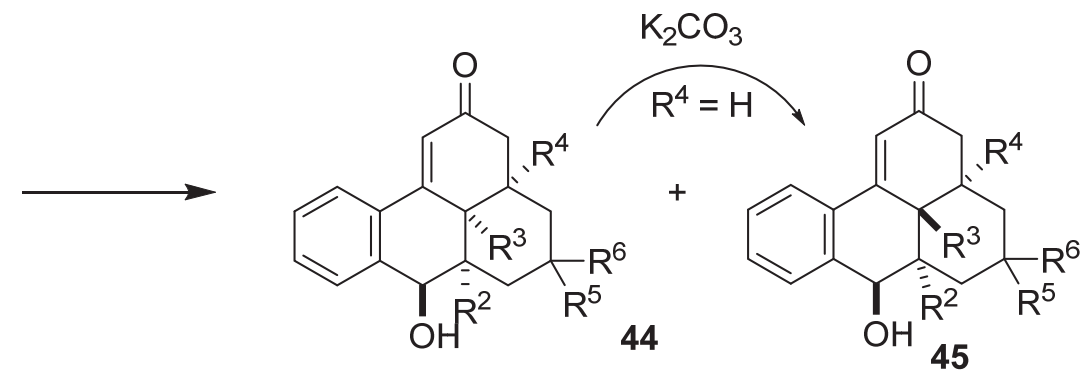

$\underline{R}^{2} \quad \underline{R}^{3} \quad \underline{R}^{4} \quad \underline{R}^{5,6} \quad \underline{\text { Yield }} \underline{\text { cis/trans }}$

$\begin{array}{llllll}\mathrm{H} & \mathrm{H} & \mathrm{H} & \mathrm{H} & 64 & 60: 40\end{array}$

$\begin{array}{llllll}\mathrm{Me} & \mathrm{H} & \mathrm{H} & \mathrm{H} & 37 & \text { varies }\end{array}$

$\mathrm{H} \quad \mathrm{Me} \quad \mathrm{H} \quad \mathrm{H} \quad 35$ varies

$\mathrm{H} \quad \mathrm{H} \quad \mathrm{Me} \quad \mathrm{Me} \quad 50 \quad 70: 30$
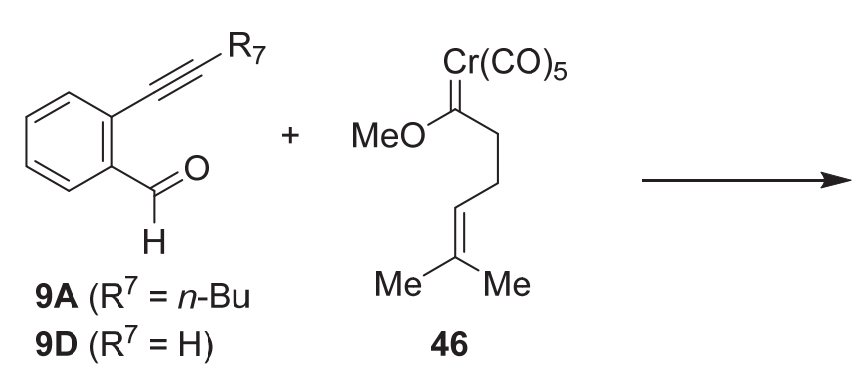

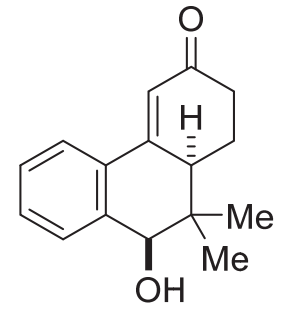

$41 \%$<smiles>COc1ccc2c(C)c(C)c3ccccc3c2c1C(C)(C)C</smiles>

If $\mathrm{I}_{2}$ added before chromatography

Scheme 10. Stereoinduction in [5+5] cycloadditions using chiral carbene complexes. 
contained in a ring system using carbene complexes of general structure 43. This was attributed to a preference for attachment to the same face of the ring as the carbene complex, and the preference is more pronounced in the transition state than in the final products. The all-equatorial compound where the $\mathrm{R}^{3}$ has isomerized (45) is energetically preferred and when $\mathrm{R}^{3}$ is $\mathrm{H}$ this isomerization readily occurs upon treatment with base. As noted in the last entry the gem dialkyl effect leads to an overall yield enhancement. In the second and third entries the alkene group is trisubstituted, which is generally not a favorable dienophile type for Diels-Alder reactions. The reaction was also examined using the sterically hindered prenyl group and still proceeded in moderate yield. ${ }^{29}$ Workup of the crude reaction mixture with iodine led to the phenanthrene system in a process where elimination of the alcohol group is accompanied by methyl migration.

\section{$2.5[5+5]$ cycloadditions using highly oxygenated benzenes for phenanthrene alkaloid syntheses}

The [5+5] cycloaddition reaction was examined as a potential key step for the preparation of the morphine alkaloid ring system, exemplified by Vicodin (Scheme 11). Key steps in the proposed synthetic route entail construction of the intermediate phenanthrene 49 through the [5+5] cycloaddition process, which greatly resembles intermediates in the successful Mulzer ${ }^{30}$ and White ${ }^{31}$ syntheses. The key carbene complex would have to bear some sort of nitrogen functionality on the alkene (e.g. 51), and the alkyne component would require an electron-rich benzene ring (e.g. 50), and neither variable had been examined up to this point. While no morphine alkaloid total synthesis was ever realized, there were some unanticipated outgrowths of this investigation arising from the proposed structural differences posed by the cycloaddition substrates. The major problem was that we were never able to synthesize the requisite nitrogen-substituted $\gamma, \delta$-unsaturated carbene complex systems. We envisaged that the only viable synthesis route would entail olefin metathesis involving an enamine and butenylcarbene complex 17A. At the time, the only carbene complex metatheses reported involved aminocarbene complexes ${ }^{32}$ and/or more stable tungsten alkoxycarbene complexes from the pre-Grubbs/Schrock era. ${ }^{33}$ Although we were able to coax several electroneutral alkenes to metathesize with carbene complex $\mathbf{1 7 A},{ }^{34}$ this process was never successful with any nitrogen-substituted alkene. Attempted alkylation of the methylcarbene complex derived anion with the in situ generated halide $\mathbf{5 3}$ was also unsuccessful due to the instability of this compound.

Several very highly oxygenated alkynylbenzaldehyde systems were examined to gauge the viability of the other aspect of morphine alkaloid synthesis requiring the use of alkynylbenzaldehydes containing highly oxygenated aromatic ring systems (Scheme 12). ${ }^{35} \mathrm{~A}$ common pathway observed for very highly electron-rich systems was dehydration of the hydrophenanthrene intermediate to afford dihydrophenanthrenes (54) as the exclusive products. The only oxygenated system examined where the hydrophenanthrenone $\mathbf{5 5}$ was the major product was the fourth entry, which features an electron-deficient oxygen group. Although folklore holds that chromium carbene chemistry must be performed under highly air and moisture free conditions, we had earlier shown that considerable amounts of water do not interfere with the chromium carbene alkyne coupling event itself. ${ }^{36}$ When 19:1 dioxane:water was employed as the solvent for this 
reaction, the yield of $\mathbf{5 5}$ improved dramatically and crude reaction mixture NMRs appeared to be much cleaner. A subsequent effort to examine water as a reaction additive was undertaken (see ahead). The system featuring a methyl ketone proceeded in lower yield that any of the others and efforts to improve the yield were initiated. In an effort to suppress the protonation event likely required for the dehydration process the hindered amine collidine was added to the reaction. Surprisingly the only effect noted was a yield enhancement and no change in the extent of dehydration. At this point two research areas were pursued: (1) syntheses of medicinally-important natural product targets containing oxygenated phenanthrene rings, and (2) investigation of the [5+5] cycloaddition reaction using non-conventional solvent systems.<smiles>COc1ccc2c3c1OC1C(=O)CC[C@]3(C)[C@H]1CN(C)C2</smiles>

Vicodin

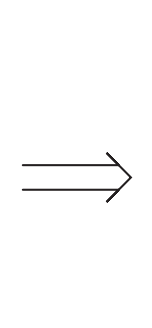<smiles>C=CCCC(OC)=C(C)OC</smiles><smiles>COC(C=O)=C([O-])[O-]</smiles><smiles>[R]c1c(OC)ccc2c1C1=CC(=O)CC[C@H]1[C@H](N(C)C(=O)CC=C)[C@H]2[X]</smiles><smiles>C#Cc1c(C=O)ccc(OC)c1O[Na]</smiles>

50
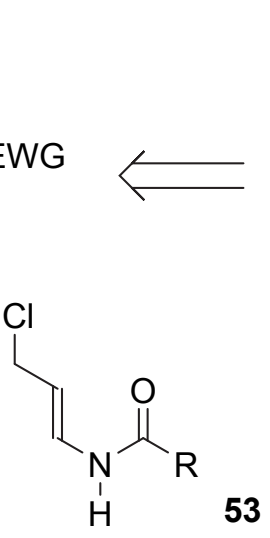

53

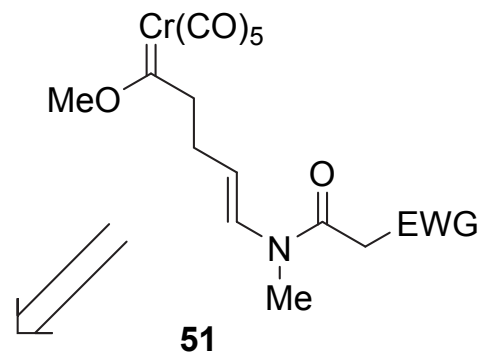

Scheme 11. Retrosynthetic analysis for morphine alkaloid synthesis using [5+5] cycloaddition.

In appreciation of the high efficiency of phenanthrene formation in Scheme 12, it was noted that numerous medicinally important target molecules contain oxygenated phenanthrene rings. The target molecule that most closely matched the oxygenation patterns of the [5+5] cycloaddition accompanied by dehydration were antofine and cryptopleurine (see the retrosynthetic analysis in Scheme 13), which display nanomolar level activity against numerous cancer cell lines, however neither of these compounds has ever been developed into a successful chemotherapeutic due to neurotoxicity of a related compound, tylocrebine. ${ }^{37}$ Efforts to generate chemotherapeutically useful analogues of antofine and cryptopleurine are still ongoing. ${ }^{38}$ Although both compounds have been synthesized many times previously, ${ }^{5,39}$ most of the existing synthetic routes follow two general protocols ( $\mathrm{C}$ ring last and addition of the $\mathrm{D}$ and $\mathrm{E}$ rings to a phenanthrene precursor). The synthesis we envisaged would employ drastically different disconnections than any previous synthesis. A key 
feature in the retrosynthetic analysis described by Scheme 13 is a simultaneous construction of the $\mathrm{B}$ and $\mathrm{C}$ rings in a single synthesis operation using a precursor that has the $\mathrm{A}$ and $\mathrm{E}$ rings intact.<smiles>[R]C(=O)c1cc([R3])c([R])c([R])c1C#CC(C)C</smiles>
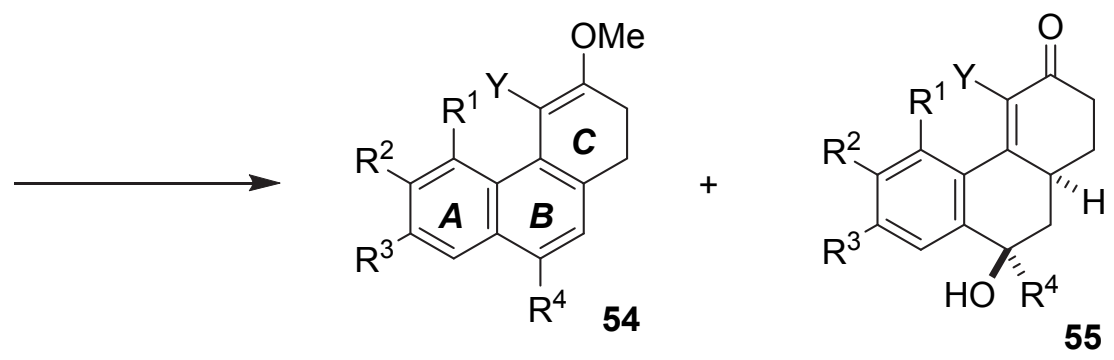

$$
\begin{array}{lllll}
\underline{R}^{1} & \underline{R}^{2} & \underline{R}^{3} & \underline{R}^{3} & \text { Yield } \\
\text { OMe } & \text { OMe } & H & H & 58 \% 54(Y=H) \\
\text { OMe } & \text { OH } & H & H & 65 \% 54(Y=T M S) \\
\text { OMe } & \text { OAc } & H & H & 63 \% 54(Y=H) \\
\text { OMe } & \text { OMs } & \text { H } & H & 52 \%(72 \% \text { with water }) 55(\mathrm{Y}=\mathrm{TMS}) \\
\mathrm{H} & \text { OMe } & \mathrm{H} & \mathrm{H} & 57 \% 54(\mathrm{Y}=\mathrm{H}) \\
\mathrm{H} & \text { OMe } & \text { OMe } & \mathrm{H} & 60 \% 54(\mathrm{Y}=\mathrm{H}) \\
\mathrm{H} & \text { OMe } & \text { OMe } & \mathrm{Me} & 40 \%(92 \% \text { with collidine }) 54(\mathrm{Y}=\mathrm{H})
\end{array}
$$

Scheme 12. $[5+5]$ cycloaddition using highly electron rich alkynylbenzaldehyde substrates.
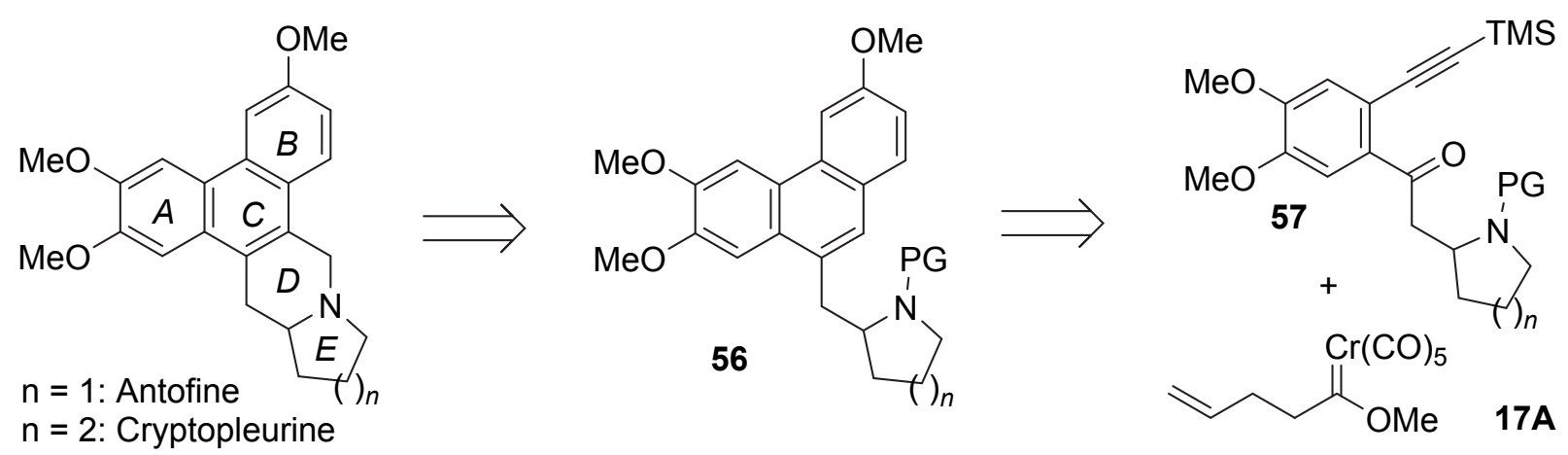

Scheme 13. Retrosynthetic analysis of phenanthrene alkaloids using [5+5] cycloaddition.

The relatively short racemic total synthesis of antofine is depicted in Scheme $14 .{ }^{40}$ The ketone 57A was prepared through silyl enol ether acyliminium ion coupling, and [5+5] cycloaddition afforded the dihydrophenanthrene, which was converted to the phenanthrene $\mathbf{5 6 \mathbf { A }}$ by thermolysis in the presence of palladium on carbon, which proceeded more cleanly and in higher yield than when using DDQ. Closure of the D ring was accomplished through Bischler-Napieralski cyclization to afford amide 59A, ${ }^{41}$ which then afforded antofine after amide reduction. ${ }^{42}$ 

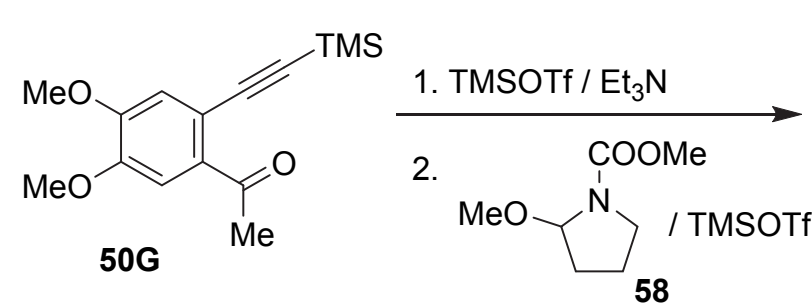
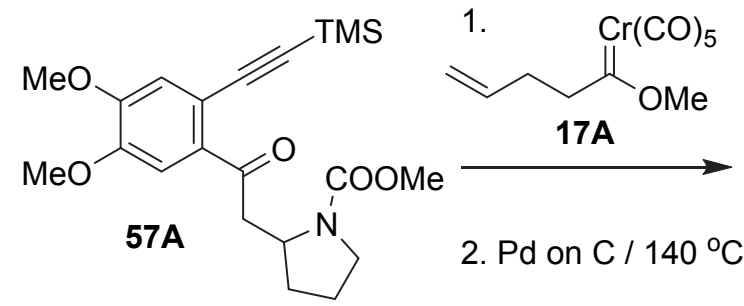
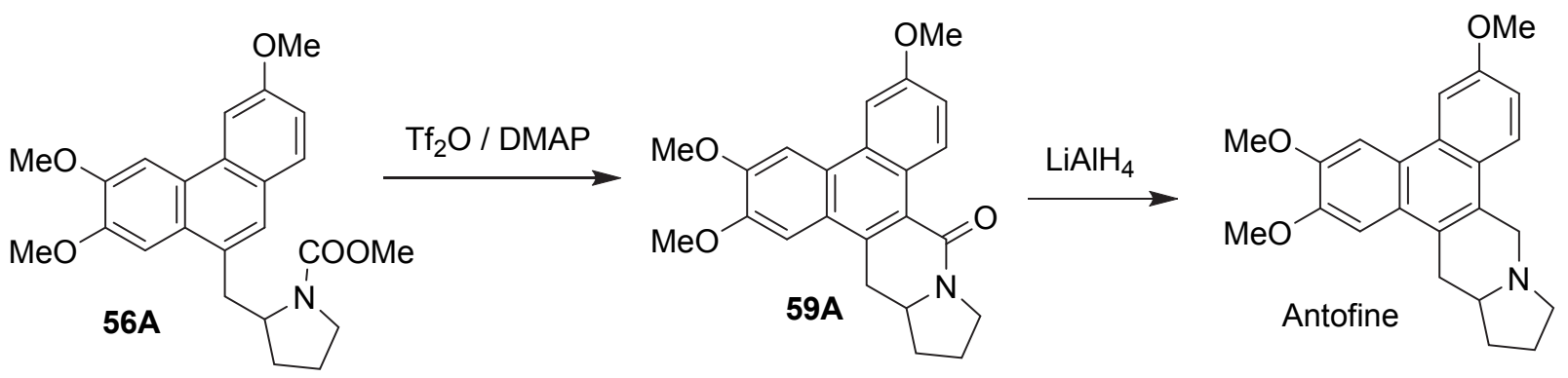

Scheme 14. Racemic synthesis of antofine.

Synthesis of enantiopure antofine would entail some other method to connect a pyrrolidine (Ering) unit with an A ring unit, which was accomplished through Sonogashira coupling of optically pure proline-derived ethynylpyrrolidine derivative 61 and 3-bromo-4-iodoveratrole (60) (Scheme 15). ${ }^{43}$ Alkyne hydration of $\mathbf{6 2}$ was fraught with problems from racemization of the only chiral center, which could be attributed to reversible Michael addition occurring from an enol intermediate. This problem could be eliminated by using a highly active mercury catalyst in place of the standard mercuric acetate and basic workup conditions. A similar set of conditions as in the previous scheme transformed 59A into the unnatural enantiomer of antofine. The analogous synthetic intermediate for homologous natural product cryptopleurine (57B), was even more prone to racemization and this problem could never be completely eliminated using the carbamate group at nitrogen. Use of the urea group throughout the synthesis, which is a poorer leaving group relative to the carbamate, avoided the racemization problem in the alkyne hydration step. The urea derivative 59C was actually a better substrate for the Bischler-Napieralski cyclization and provided the natural enantiomer of cryptopleurine. The Bischler-Napieralski reaction using ureas proved to be a moderately effective general method for amidocarboxylation of electron-rich aromatics. ${ }^{44}$ Silicon fell off during purification of the [5+5] cyclization product during the racemic synthesis, however in the optically active synthesis a couple of years later it remained, and was removed through [5+5] cycloaddition and dehydrogenation in a sequential no-purification reaction. The silicon group was lost as the phenanthrene compound was purified, and the ease is likely related to the silicon group's instability in the bay region. We attribute the silicon loss issue to the differing quality of Flash-grade silica gel used in intervening years. 

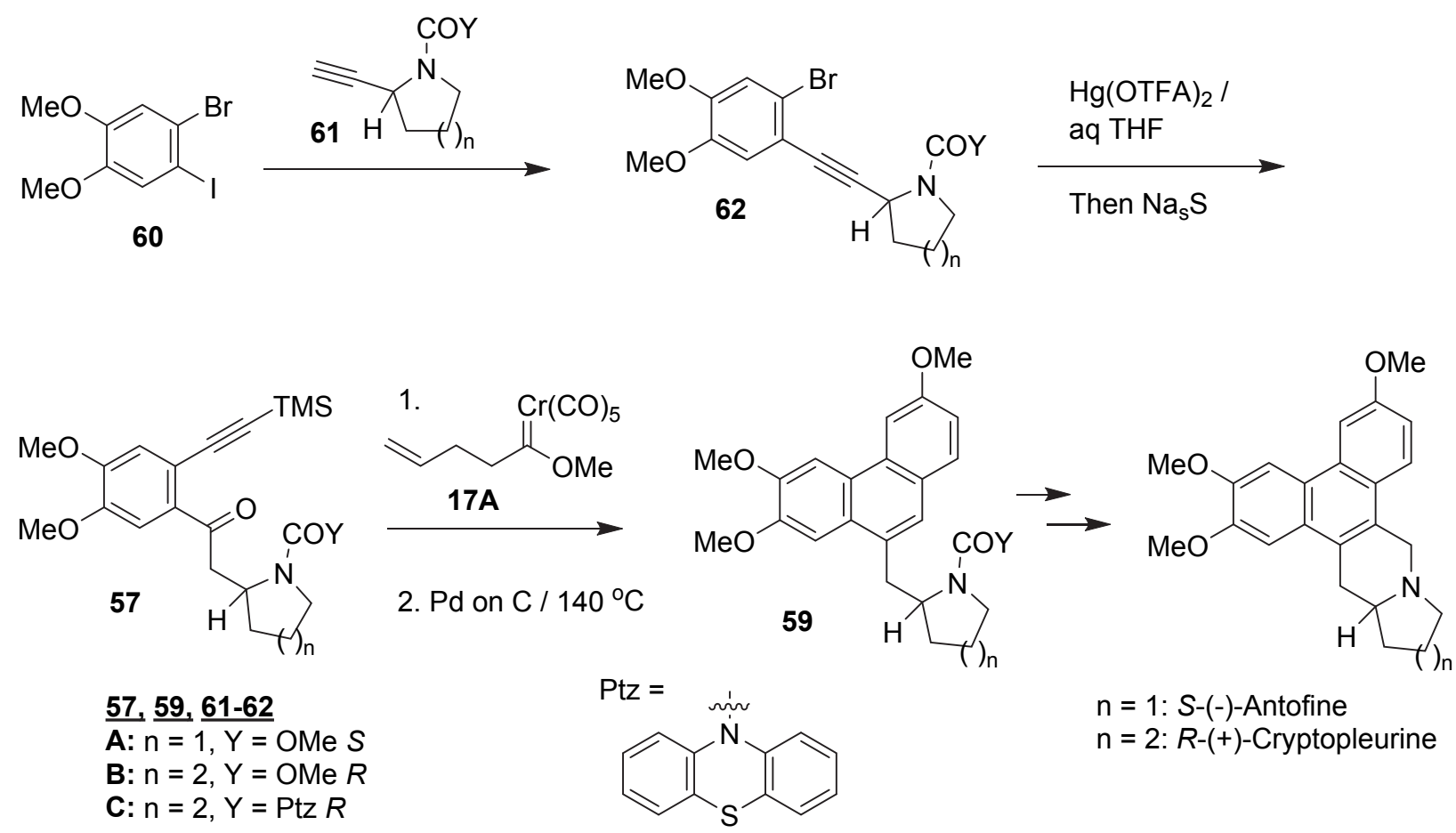

Scheme 15. Total synthesis of enantiopure antofine and cryptopleurine.

\section{6 [5+5] Cycloaddition reactions in hydroxylic solvents}

Since water was a beneficial additive in the above studies in Scheme 12, the [5+5] cycloaddition process was examined in the presence of much higher amounts of water (Scheme 16). ${ }^{45}$ The reaction could in fact be performed in virtually any solvent. Even pure water could be employed if a surfactant was added, however the degree of foaming in the reaction flask and condenser plus emulsions during extractive work-ups made the process somewhat messy. The yield was the same using the surfactant sodium dodecyl sulfate (SDS) as simply "grabbing a wad of hand soap from the bathroom and tossing it into the reaction flask." A side benefit from these studies is that chromium hexacarbonyl sublimes onto the side of the condenser and can be recovered from the reaction in highly pure form simply by scraping the condenser in reactions that contain some degree of water. Since chromium hexacarbonyl was the original chromium source used to prepare the carbene complex this constitutes a process that is overall less than stoichiometric in chromium. The effect was most dramatic using the silylated alkyne-aldehydes. The terminal alkyne reactions in the presence of water led predominantly to alkylidenephthalans (e.g. 63) due to a rapid hydrolysis of the enol ether group. 


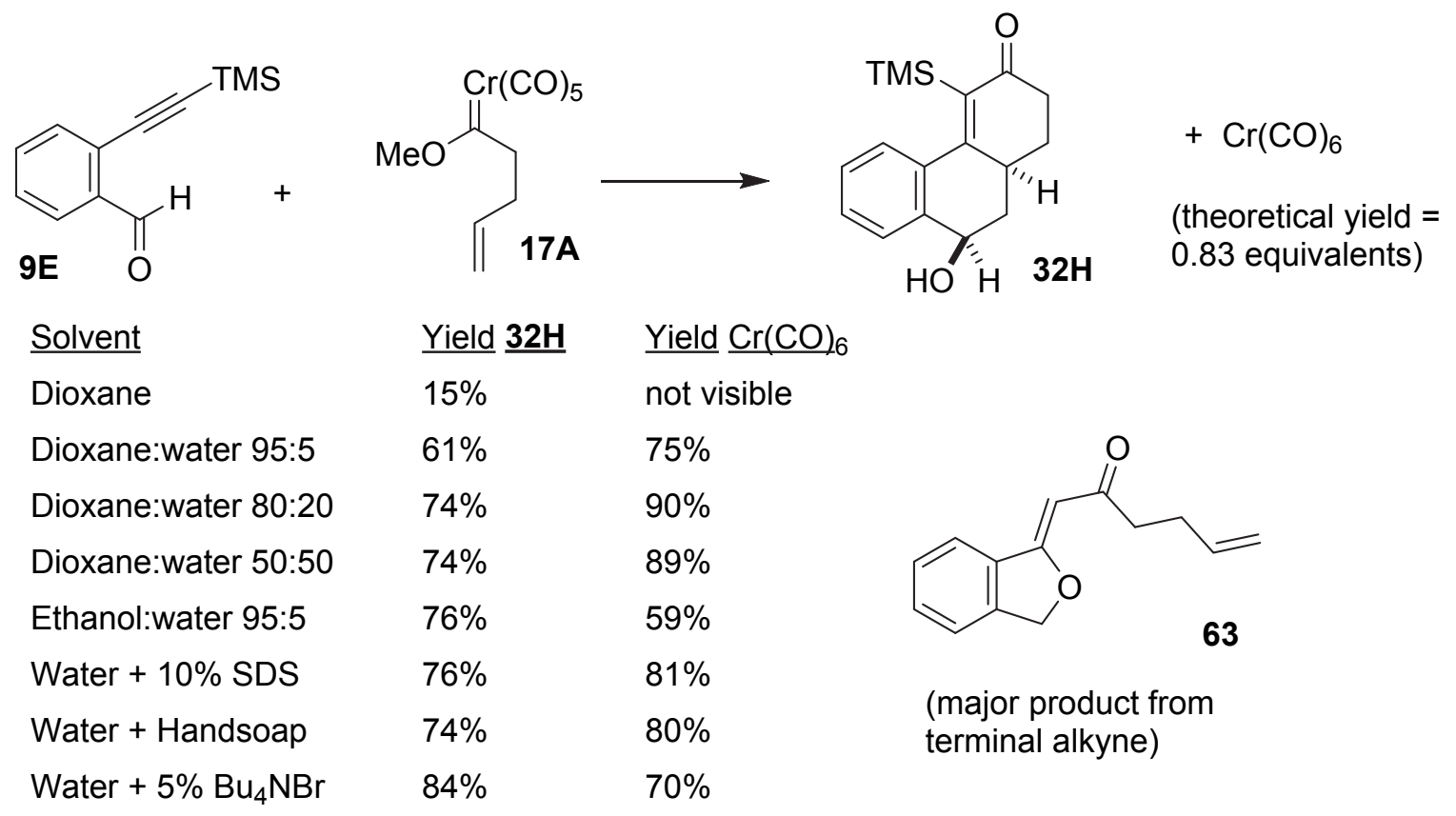

Scheme 16. [5+5] cycloaddition in the presence of water or ethanol.

\subsection{Syntheses of phenalene systems using [5+5] cycloaddition}

Numerous studies of the [5+5]-cycloaddition have focused on the preparation of phenalene systems and their nitrogen analogs aporphines (Scheme 17). ${ }^{46}$ Initially compounds having a ring fused derivative (e.g. 64) were investigated as [5+5] cycloaddition substrates in anticipation that superior yields and efficiency would result since the carbonyl group is frozen into the correct conformation for the cyclization event. Several of these derivatives were prepared and successfully engage in the [5+5] for the six-membered ring (tetralone) case but not for the five-membered ring (indanone) case due to ring strain in the isobenzofuran intermediate. As noted in a previous section, the product identity (66 versus 67) could be controlled through the presence or absence of water in the solvent system. A quicker approach to the phenalene ring system involves a double [5+5] cycloaddition process emanating from the easily-prepared bis(alkyne) derivative 68. The double [5+5] process using alkyne 68 requires intermediate oxidation of initially produced alkyne-ketoalcohol 69 to alkyne-diketone 70, and rapidly adds four new rings to assemble a doubly-annulated phenalene ring system (71 and 72). Identification of the major stereoisomer as $\mathbf{7 1}$ was easily accomplished through symmetry considerations since the major isomer possesses a plane of symmetry and displays only thirteen ${ }^{13} \mathrm{C}$ NMR signals. We have dubbed this the chromium 0-6-0 approach for rapid construction of complex ring systems having a phenalene core. 

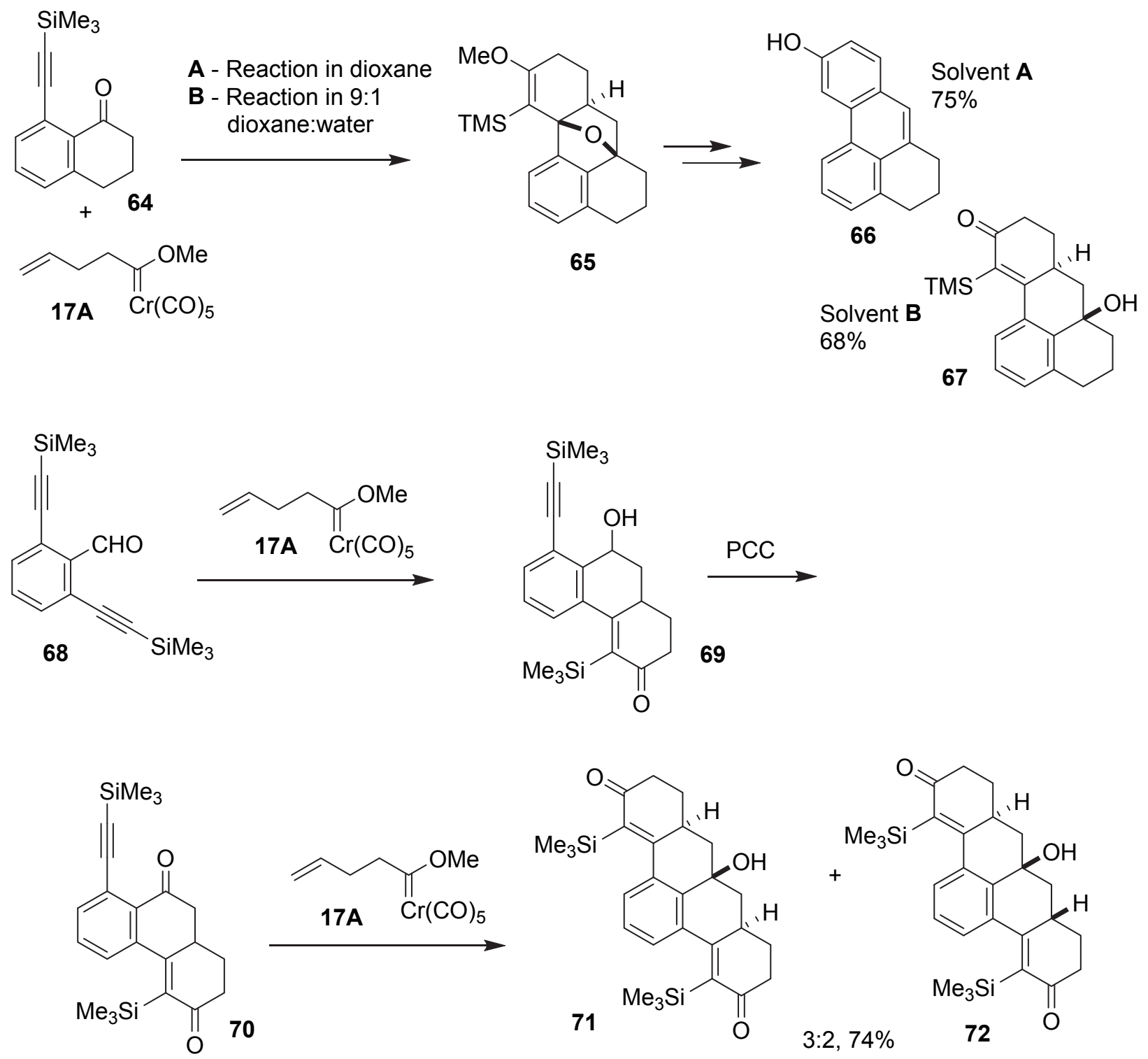

$65 \%(2$ steps)

Scheme 17. Phenalene-based [5+5] cycloaddition processes.

\subsection{Approaches to aporphine alkaloid ring systems}

Attempts to transform related compounds into the aporphine system are shown in Scheme 18. We noted that if the aminoethyl entity is present in the starting material the [5+5] cycloaddition reaction fails, presumably due to keto-hemiaminal issues, which are evident in the ${ }^{1} \mathrm{H}$ NMR spectra of the starting compounds. Attempted anti-Markovnikov hydration of the terminal alkyne $\mathbf{8 0}$ (derived from compound $\mathbf{7 0}$ in Scheme 17) afforded exclusively the methyl ketone derivative (81) ${ }^{47}$ and not the desired aldehyde (82), which can likely be attributed to neighboring group participation by the benzylic carbonyl group of $\mathbf{8 0} .^{48}$ The amide $\mathbf{8 3}$ was examined as a substrate for the [5+5] cycloaddition, however a complex reaction mixture resulted from treating this compound with carbene complex 17A and none of the expected isoquinoline 84 was observed in this reaction. 
<smiles>Brc1cccc(I)c1</smiles>

73
1. LDA, then DMF

2. $\equiv$ TMS

I Pd \& Cu catalysts<smiles>C#Cc1cccc(Br)c1C=O</smiles>

1.<smiles>C=CCCC(=CC(=O)OC)C(=O)OC</smiles>

2. PCC

74 $\mathrm{SiMe}_{3}$<smiles>C[SiH3]C1=C2c3cccc(Br)c3C(=O)CC2CCC1=O</smiles><smiles>CN(CC[B-]Br)C(=O)OCC(=O)OCc1ccccc1</smiles>

75<smiles>CN1CCc2cccc3c4c(cc1c23)CCC(=O)C4</smiles><smiles>CN1CCc2cccc3c2c1cc1ccc(O)cc13</smiles>

Net Addition of $\mathrm{H}_{2} \mathrm{O}$

79<smiles>CC(=O)N(C)CCc1cccc2c1C(=O)CC1CCC(=O)C(Cl)=C21</smiles><smiles>COC(=O)C(Cl)Cl</smiles><smiles>CS(=O)(=O)C#Cc1cccc2cc[nH]c(=O)c12</smiles>

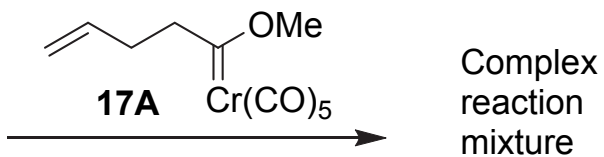

83<smiles>CC(=O)c1cccc2c1C(=O)CC1CCC(=O)C([Si])=C21</smiles><smiles></smiles>

observed

82<smiles>CS(=O)(=O)C1=C2c3cccc4ccnc(c34)CC2CCC1=O</smiles>

Not observed

\section{4}

Scheme 18. Synthetic approaches to apomorphine using [5+5] cycloaddition. 
Success was realized by employing the Molander aminoethylation procedure ${ }^{49}$ after the [5+5] cycloaddition using bromoarene substrate 75. Removal of the carbamate protecting group from Nmethyl compound $\mathbf{7 7}$ led surprisingly to the phenanthrene system 79, which was attributed to unanticipated air oxidation of the expected ketone product 78. Phenanthrene 79 differs from apomorphine's molecular formula by a water molecule, and requires a hydroxylation and hydrogenation step to transform into apomorphine. ${ }^{50}$ Unfortunately, efforts to introduce the remaining oxygen using a variety of oxidants met with failure.

\subsection{Use of amide carbonyl groups in the $[5+5]$ cycloaddition}

All of the examples in the previous schemes employ aldehydes or ketones as the carbonyl group of the alkyne-carbonyl partner. Other carbonyl groups are less efficient than ketones and aldehydes. Esters do not engage in the critical isobenzofuran formation pathway at all, which was attributed to the lesser nucleophilicity of this carbonyl group. Amides do undergo the desired pathway, however there are side reactions that lead to generally less efficient [5+5] cycloaddition processes (Scheme 19).$^{51}$ Coupling of $o$-alkynylbenzamide 85 and $\gamma, \delta$-unsaturated carbene complexes $\mathbf{1 7 A} / \mathbf{E}$ afforded [5+5] cycloaddition products (89 or 90) accompanied by alkyne insertion - intramolecular cyclopropanation products (92). ${ }^{52}$ Observation of this side reaction in amide substrates was attributed to the enhanced stability of the amide carbonyl group, which causes the initiallygenerated carbene complex to engage in other reaction pathways despite the higher nucleophilicity of this carbonyl group. Attempts to affect the product distribution through possible transmetallation to rhodium ${ }^{53}$ led to a slight enhancement in the yield of [5+5] cycloaddition products. The systems where the dienophile is tethered to the amide nitrogen cannot readily undergo the cyclopropanation reaction without forming a macrocycle, and these reactions led to more efficient formation of isobenzofuran Diels-Alder adducts.

\subsection{Use of heteroaromatic systems in the $[5+5]$ cycloaddition}

When the benzene ring was replaced by a heteroaromatic system (97, Scheme 20$)$ a mechanistically different net [5+5] cycloaddition reaction pathway was followed, leading to fused ring hydronaphthalenones (102 or 104). ${ }^{54,55}$ In some of the more electron-rich heteroaromatic systems, the traditional [5+5] cycloaddition pathway leading to analogous fused ring systems (100) was a competitive process. The reaction of carbene complexes and 3-alkynylthiophene-2-carboxaldehydes led to heterocyclic annulated pyrone systems (101), which also engage in Diels-Alder reactions to afford the bridged structures (102). The reactive intermediates in these cases were stable compounds that could be isolated. The different reaction pathway in these systems was attributed to the enhanced ring strain in the furan-fused bicyclo[3.3.0] systems (99). ${ }^{56}$ The thiophene systems produced predominantly pyrone products 102. The critical CO insertion process required for pyrone formation is typically suppressed in highly electron-rich systems, ${ }^{57}$ and thus this pathway was not exclusive for more electron-rich partners. The furan systems produced exclusively the pyronederived products 104. In this case the initially produced pyrone Diels-Alder adducts (102) undergo a stepwise decarboxylation process, which could be suppressed if there was an electron- 
withdrawing group on the furan ring. Imidazole versions of compound $\mathbf{9 7}$ also afforded products<smiles>[R]C=CCCC(OC(C(=O)OC)C(=O)OC)C(=O)NC(=O)c1ccccc1C#C</smiles><smiles>[R]C=CCCC(C)=CC(=O)OC</smiles>
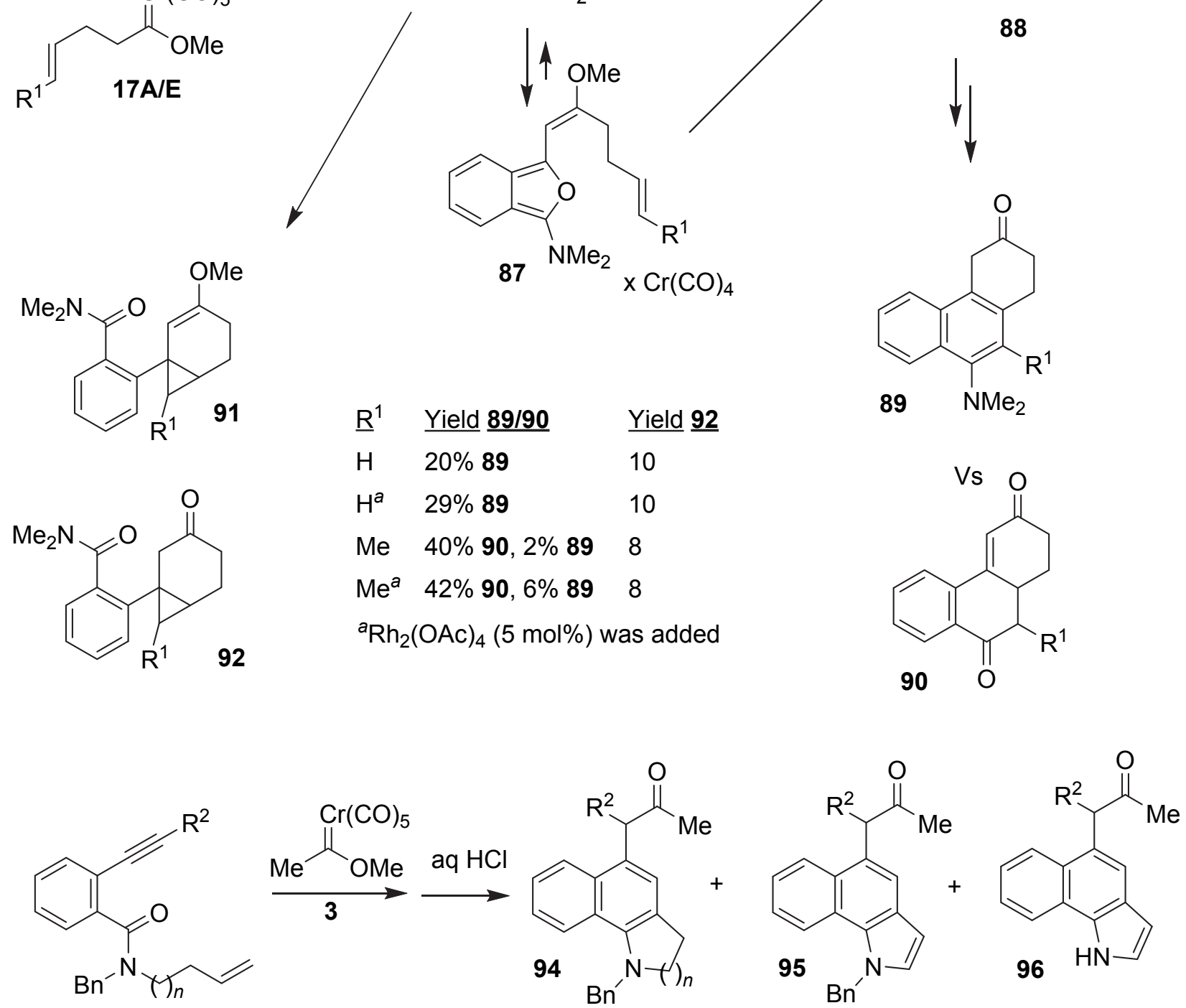

93

$\begin{array}{lllll}\underline{\mathrm{R}}^{2} & \underline{n} & \underline{\mathbf{9 4}} & \underline{\mathbf{9 5}} & \underline{\mathbf{9 6}} \\ \mathrm{H} & 1 & 46 \% & 9 \% & 0 \% \\ n-\mathrm{Bu} & 1 & 0 \% & 45 \% & 22 \% \\ \mathrm{H} & 2 & 20 \% & \text { n/a } & \text { n/a } \\ n-\mathrm{Bu} & 2 & 55 \% & \text { n/a } & \text { n/a }\end{array}$

Scheme 19. Amides in the [5+5] cycloaddition and related reactions. 
derived from pyrone Diels-Alder reaction followed by decarboxylation. The indole analog (the pyrrole ring of indole replaces the furan/thiophene ring systems of 97) produced either pyrone or fused furan-derived products, depending on the group at nitrogen. The electron donating benzyl protecting group favored fused furan-derived products while the electron-deficient tosyl-protected indoles favored pyrone-derived products.

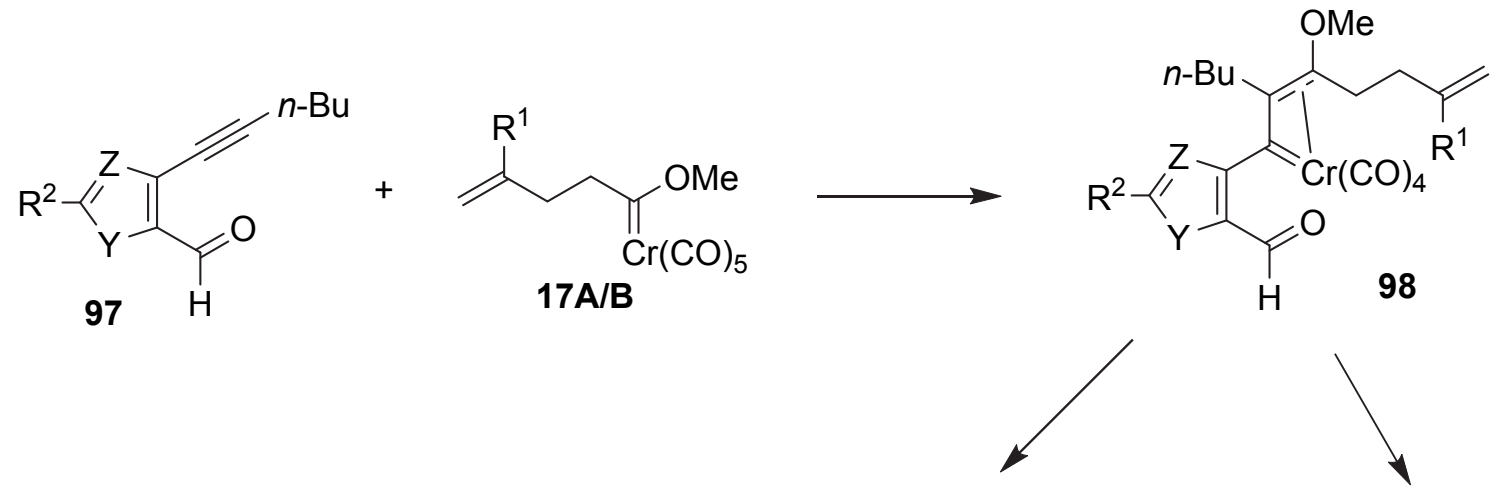

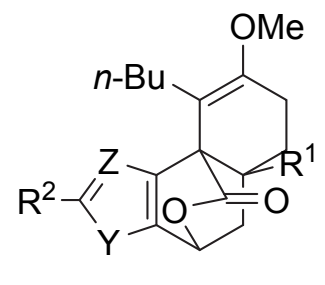

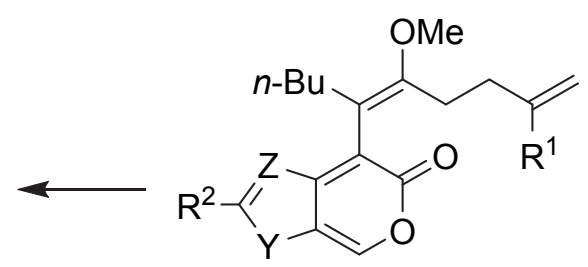

101

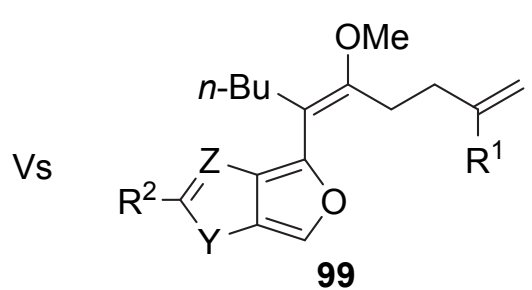

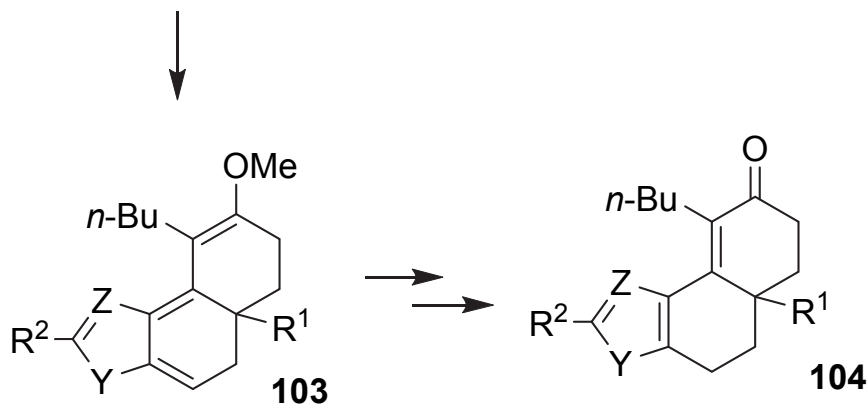

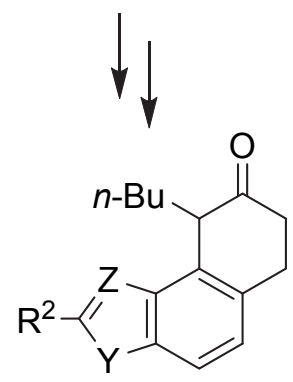

$\begin{array}{llllllll}\underline{Y} & \underline{\mathrm{Z}} & \underline{\mathrm{R}}^{1} & \underline{\mathrm{R}}^{2} & \underline{\mathbf{1 0 2}} & \underline{\mathbf{1 0 0}} & \underline{\mathbf{1 0 4}} & \underline{\text { solvent }} \\ \mathrm{S} & \mathrm{CH} & \mathrm{H} & \mathrm{H} & 56 \% & 16 \% & 0 \% & \mathrm{THF} \\ \mathrm{O} & \mathrm{CH} & \mathrm{H} & \mathrm{H} & 0 \% & 0 \% & 73 \% & \text { dioxane } \\ \mathrm{O} & \mathrm{CH} & \mathrm{Me} & \mathrm{H} & 0 \% & 0 \% & 65 \% & \text { dioxane } \\ \mathrm{O} & \mathrm{CH} & \mathrm{H} & \mathrm{COOMe} & 64 \% & 0 \% & 7 \% & \text { dioxane } \\ \mathrm{NBn} & \mathrm{N} & \mathrm{H} & \mathrm{Ph} & 0 \% & 0 \% & 55 \% & \text { dioxane } \\ \text { N-PBRib } & \mathrm{N} & \mathrm{H} & \mathrm{H} & 0 \% & 0 \% & 40 \% & \text { dioxane }\end{array}$

Scheme 20. $[5+5]$ cycloadditions using five-membered ring heterocycle carboxaldehydes. 


\subsection{Use of triply bonded systems in the [5+5] cycloaddition}

Extension of the [5+5] cycloaddition process to triple bonded systems was demonstrated for $o$-alkynylphenylcarbene complexes $(\mathbf{1 0 5}$, Scheme 21$)$, which led to polycyclic aromatic systems. ${ }^{58}$

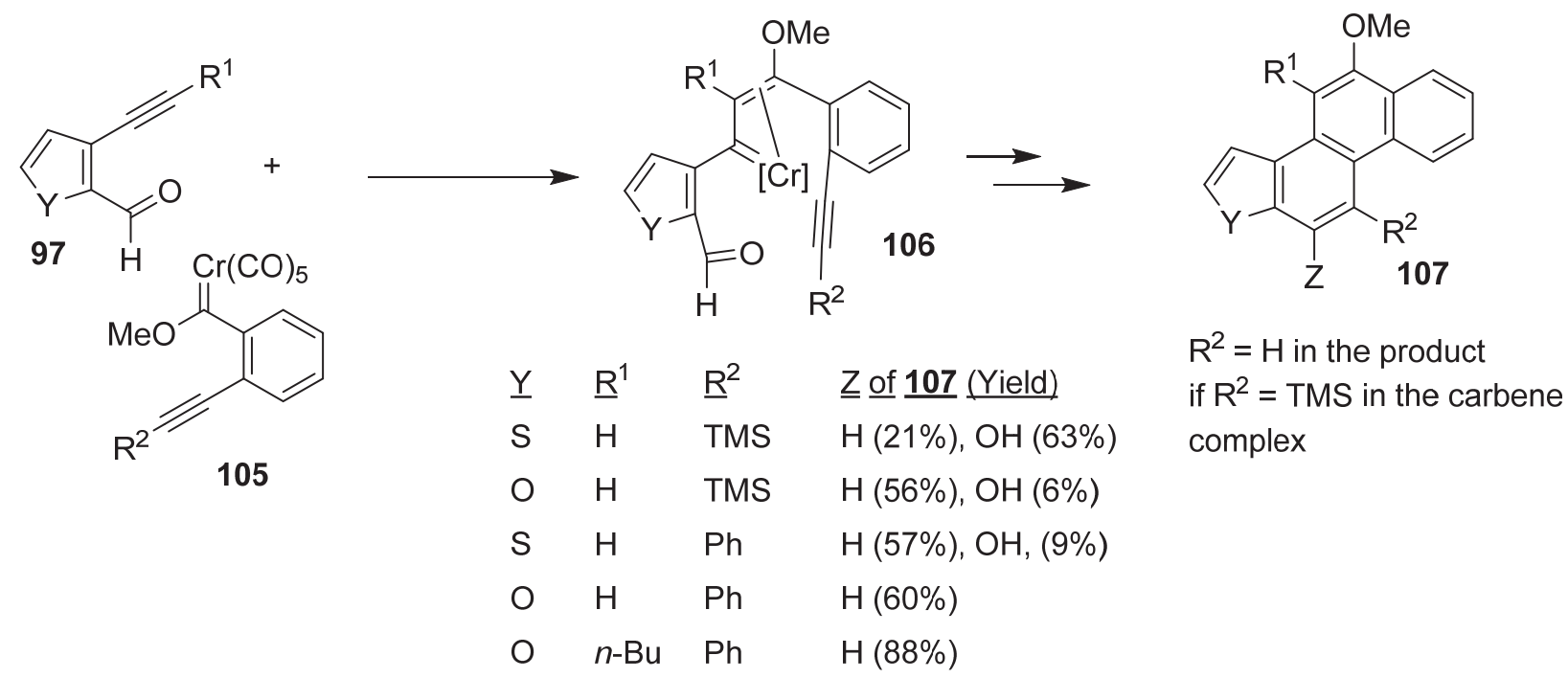<smiles>[R]C#Cc1ccccc1C([R])=O</smiles><smiles>[R3]OC(=O)/C=C(/[X])C#N</smiles><smiles>[X]C(=C([O-])[O-])c1ccccc1C#N</smiles>

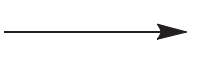<smiles>[R]c1c([X])c([R])c2c(cc([R])c3ccccc32)c1[R]</smiles>

110: dihydrophenanthridine<smiles>[X]c1ccc2cc([R])c3ccccc3c2c1[R]</smiles>

111: phenanthridine or benzophenanthridine 112: ketone from hydrolysis of 110

$\begin{array}{llllll}\underline{\mathrm{R}}^{1} & \underline{\mathrm{R}}^{2} & \underline{\mathrm{R}}^{3} & \underline{\mathrm{R}}^{4} & \underline{\mathrm{X}} & \underline{\text { Yield }} \\ n-\mathrm{Bu} & \mathrm{H} & \mathrm{CH}_{2} \mathrm{CN} & \mathrm{H} & \mathrm{OMe} & 40 \% 110,36 \% 113 \\ n-\mathrm{Bu} & \mathrm{H} & n-\mathrm{Pr} & \mathrm{H} & \mathrm{OMe} & 53 \% 111 \\ \mathrm{H} & \mathrm{H} & \mathrm{R}^{3,4}=-\left(\mathrm{CH}_{2}\right)_{4} & & \mathrm{NMe}_{2} & 42 \% 112 \\ n-\mathrm{Bu} & \mathrm{H} & n-\mathrm{Pr} & \mathrm{H} & \mathrm{NMe}_{2} & 37 \% 111 \\ n-\mathrm{Bu} & \mathrm{Ph} & \text { Benzo-fused System } & \mathrm{NMe}_{2} & 59 \% 111\end{array}$

Scheme 21. [5+5] Cycloadditions using carbene complexes possessing a $\gamma, \delta$-triple bond.

Initially it was thought that this coupling reaction would be restricted to terminal alkynylbenzoyl partners due to competing intermolecular reaction with the alkyne group of another carbene complex molecule, however no noticeable yield reduction was noted for the one example where this coupling partner possessed an internal alkyne group. The reaction produces mixtures of phenolic and the corresponding deoxy compounds $(107, \mathrm{Z}=\mathrm{H})$, depending on the identity of the alkyne group of the carbene complex. The reaction using the nitrile-containing carbene complexes (108, 
109) similarly afforded polycyclic aromatic ring systems containing a core pyridine ring system (110-113). ${ }^{59,60}$ Reduced stability was noted for $\beta$-cyanocarbene complexes thus both alkoxy and aminocarbene complexes were examined. The mechanism for the reactions in Scheme 21 are unclear since a myriad of pathways are available to the vinylcarbene complex intermediate (106), including the previously-invoked furan and pyrone-based pathways and an intramolecular alkyne insertion pathway. ${ }^{61}$ Computational modeling of the nitrile reactions revealed that the isobenzofuran nitrile Diels-Alder reaction was highly endothermic (the reverse had been observed experimentally) ${ }^{62}$ unless coupled with the reductive aromatization process.

\section{$2.12[5+6]$ cycloaddition approach to benzocycloheptanes}

A final consideration concerns the effect of longer carbene complex-alkene tethers on the efficacy of the intramolecular Diels-Alder step (Scheme 22). The coupling reaction using $\delta, \varepsilon$-unsaturated carbene complexes (114) resulted in a net [5+6] cycloaddition process. ${ }^{63}$ This reaction proved to be general for a variety of substitution patterns. The acidic workup resulted in primarily the aminonaphthalenes (115), while in one system the alcohol ketone (116) was produced despite the acidic workup conditions. An elimination product (117) was produced when the propargylic ester was employed. Longer tethers and arylcarbene complexes were not tolerated. The preferred reaction pathway for arylcarbene complexes was intramolecular cyclopropanation, which had previously been observed by others as a direct thermal reaction not involving alkynes. ${ }^{64}$
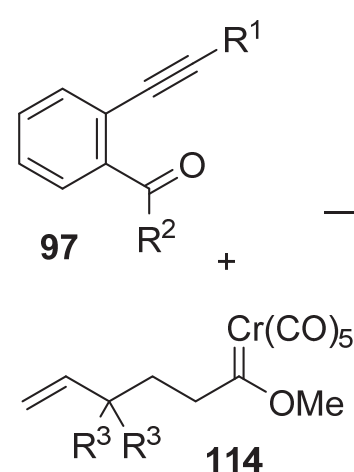

114

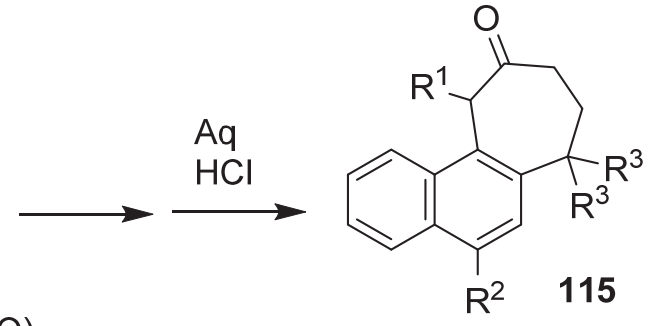

$\underline{\mathrm{R}}^{1}$

TMS

TMS

TMS

$\mathrm{H}$

$n-\mathrm{Bu}$

$\mathrm{CH}_{2} \mathrm{OAC}$
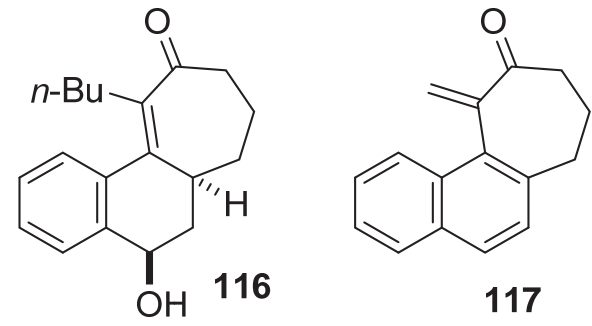

117

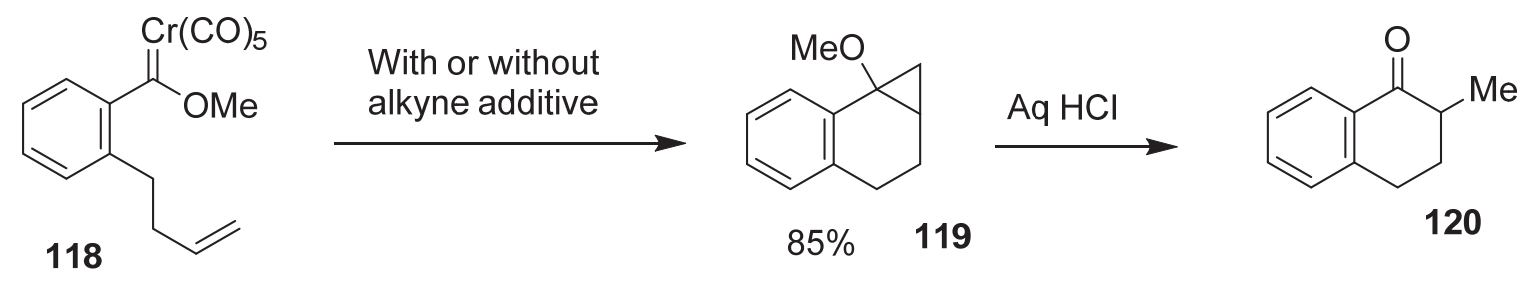

Scheme 22. Tandem isobenzofuran formation - Diels-Alder reactions employing longer tethers. 


\subsection{Other studies of $[5+5]$ cycloaddition}

Additional reaction processes inspired by studies of the [5+5]-cycloaddition are depicted in Scheme 23. Attempts to extend this reaction system to imine analogs (121) proceeding through isoindole intermediates (122) were unsuccessful in [5+5] cycloaddition because the isoindole ring system was insufficiently reactive with unactivated dienophiles, however these proved useful in the threecomponent coupling systems using electron-deficient alkyne additives due to the enhanced stability of isoindoles relative to isobenzofurans. ${ }^{18}$ The reaction with non-aromatic precursor compounds (124) was less general, however the Diels-Alder steps did occur at high temperatures in very polar solvents, where dehydration occurs in situ to form the aromatic products (126). ${ }^{65}$ The dienophile alkene group can be tethered to the alkyne group (e.g. enynal 127) to afford 5,6- and 5,7-fused ring systems (130) upon treatment with carbene complexes in a similar pathway involving isobenzofuran (128) formation followed by intramolecular Diels-Alder reaction accompanied by opening of the resulting oxanorbornene ring (129). ${ }^{66}$ Numerous additional examples of the [5+5] cycloaddition reactions using nitrogenated aromatic carboxaldehyde precursors were reported by our former associate, Binay Ghorai, in his independent academic career. ${ }^{67}$

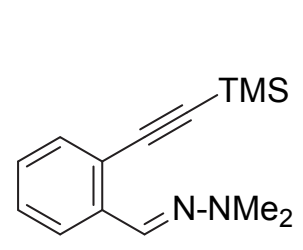

121

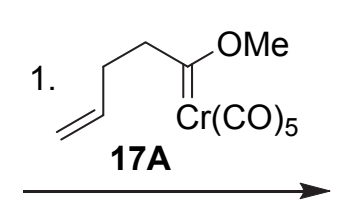

2. DMAD

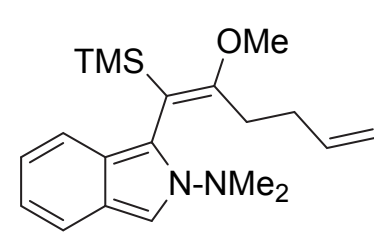

122 (No intramolecular Diels-Alder product observed)<smiles>C=CCC/C(OC)=C(/SCCC)c1c(C(=O)OC)c(C(=O)OC)cc2ccccc12</smiles>

123<smiles>C=CCC/C(OC)=C(/SCCCC)c1occ2c1CCC2</smiles>

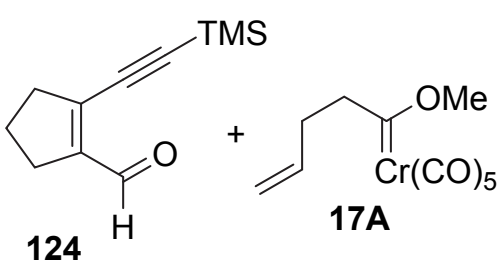

1. $85^{\circ} \mathrm{C} /$ Dioxane

2. Replace dioxane with DMF / $145^{\circ} \mathrm{C}$

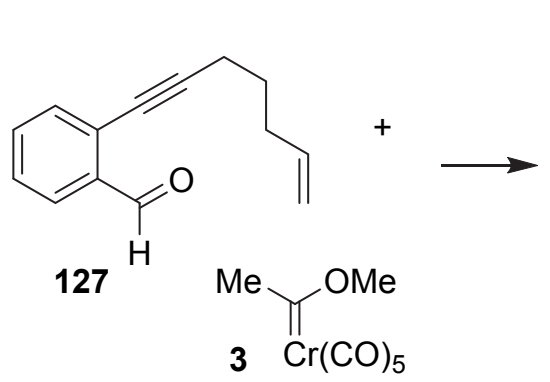<smiles>CO/C(C)=C(\CCCCI)c1occ2ccccc12</smiles>

128<smiles>CO/C(C)=C1\CCC[C@H]2C[C@H]3O[C@]12c1ccccc13</smiles>

129<smiles>C=C(OC)C1=C2c3ccccc3[C@@H](O)C[C@H]2CCC1</smiles>

130

Scheme 23. Other studies related to [5+5] cycloaddition. 


\section{Conclusions and Outlook}

In summary, we have embarked on a multiyear study of the design and execution of a novel [5+5] cycloaddition reaction and have demonstrated its utility through several complete and partial total synthesis efforts. Although the process uses chromium, the form used is in a lower oxidation state (zero) far from the plus six oxidation state associated with environmental hazards. In a study of a multistep no chromium alternative, three additional steps are required to produce similar compounds from equivalent $o$-alkynylbenzaldehyde starting materials. ${ }^{68}$ The one-step [5+5] cycloaddition reaction results in the formation of three new carbon-carbon bonds, the first one intermolecular. The overall design allows one to perform several operations in one reaction event and avoids all of the extra chemicals, solvents, and labor of four reaction steps, thus resulting in a net reduction in the overall waste stream. Although the multistep alternative proceeds in more steps, we are currently exploring other mechanistically related catalytic alternatives for the generating isobenzofurans/isoindoles that feature alkene groups suitably located for these ring forming processes. We are exploring different methods to manipulate the oxygen-bridged intermediates that currently enter into Lewis acid-based pathways, which would translate to a more general approach to diverse phenanthrene-based natural products. Finally we are examining alternative synthetic routes to $\gamma, \delta$-unsaturated Fischer carbene complexes since structural limitations that center on this reacting partner proved to be the major impediment in two of the proposed synthetic projects.

\section{Acknowledgements}

The research outlined in this account were funded by the Science Foundation, the SCORE program of the National Institutes of Health (S06GM003136, 1SC1GM-083693, 5SC3GM111131), and New Mexico State University. We are grateful to the reviewers for their thorough analysis and comments.

\section{References}

1. $\quad$ https://en.wikipedia.org/wiki/Cycloaddition

2. Mackay, E. G.; Sherburn, M. S. Synthesis 2015, 47, 1-21.

http://dx.doi.org/10.1055/s-0034-1378676

3. Zezula, J.; Hudlicky, T. Synlett 2005, 388-405.

http://dx.doi.org/10.1055/s-2005-862383

4. Zhang, A.; Zhang, Y.; Branfman, A. R.; Baldessarini, R. J.; Neumeyer, J. L. J. Med. Chem. 2007, 50, 171-191.

http://dx.doi.org/10.1021/jm060959i

5. S. Chemler, Curr. Bioact. Comp. 2009, 5, 2-19. http://dx.doi.org/10.2174/157340709787580928 
6. Choi, Y. L.; Kim, B. T.; Heo, J. N. J. Org. Chem. 2012, 77, 8762-8767.

http://dx.doi.org/10.1021/jo301345a

7. Harvey, R. G. Curr. Org. Chem. 2004, 8, 303-323.

http://dx.doi.org/10.2174/1385272043485918

8. Joistgen, O.; Pfletschinger, A.; Ciupka, J.; Dolg, M.; Nieger, M.; Schnakenburg, G.; Frohlich, R.; Kataeva, O.; Dotz, K. H. Organometallics 2009, 28, 3473-3484.

http://dx.doi.org/10.1021/om900057a

9. Semmelhack, M. F.; Ho, S.; Cohen, D.; Steigerwald, M.; Lee, M. C.; Lee, G.; Gilbert, A. M.;

Wulff, W. D.; Ball, R. G. J. Am. Chem. Soc. 1994, 116, 7108-7122.

http://dx.doi.org/10.1021/ja00095a014

10. Koo, S.; Liebeskind, L. S. J. Am. Chem. Soc. 1995, 117, 3389-3404.

http://dx.doi.org/10.1021/ja00117a009

11. Chang, C. F.; Li, C. F.; Tsai, C. C.; Chuang, T. H. Org. Lett. 2016, 18, 638-641. http://dx.doi.org/10.1021/acs.orglett.5b0

12. Waters, M. L.; Wulff, W. D. Org. Reactions 2008, 70, 121-623.

http://dx.doi.org/10.1002/0471264180.or070.02

13. Herndon, J. W.; Tumer, S. U.; McMullen, L. A. J. Am. Chem. Soc. 1992, 114, 8394-8404. http://dx.doi.org/10.1021/ja00048a008

14. Herndon, J. W.; Hayford, A. Organometallics 1994, 14, 1556-1558.

http://dx.doi.org/10.1021/om00004a005

15. Herndon, J. W.; Wang, H. J. Org. Chem. 1998, 63, 4564-4565.

http://dx.doi.org/10.1021/jo9803939

16. Friedrichsen, W. Adv. Heterocycl. Chem. 1999, 73, 1-96.

http://dx.doi.org/10.1016/S0065-2725(08)60940-X

17. Jiang, D.; Herndon, J. W. Org. Lett.2000, 2, 1267-1269.

http://dx.doi.org/10.1021/o1005691i

18. Duan, S.; Sinha-Mahapatra, D. K.; Herndon, J. W. Org. Lett. 2008, 10, 1541-1544. http://dx.doi.org/10.1021/o1800242n

19. McCallum, J. S.; Kunng, F. A.; Gilbertson, S. R.; Wulff, W. D. Organometallics 1988, 7, 2346- 2360.

http://dx.doi.org/10.1021/om00101a015

20. Barluenga, J.; Fernández-Acebes, A.; Trabanco, A. A.; Flórez, J. J. Am. Chem. Soc. 1997, 119, 7591-7592.

http://dx.doi.org/10.1021/ja970924v

21. Meiners, U.; Cramer, E.; Froehlich, R.; Wibbeling, B.; Metz, P. Eur. J. Org. Chem. 1998, 2073-2078.

http://dx.doi.org/10.1002/(SICI)1099-0690(199810)1998:10<2073::AID-

EJOC2073>3.0.CO;2-D

22. Amin, S. R.; Sawant, S. S.; Puranik, V. G.; Sarkar, A. Organometallics 1996, 14, 3617-3619. http://dx.doi.org/10.1021/om00008a004

23. Moser, W. H.; Hegedus, L. S. J. Am. Chem. Soc. 1996, 118, 7873-7880. 
http://dx.doi.org/10.1021/ja9537585

24. Semmelhack, M. F.; Lee, G. R. Organometallics 1987, 6, 1839-1844.

http://dx.doi.org/10.1021/om00152a002

25. Barluenga, J.; Flórez, J.; Fañanás, F. J. J. Organomet. Chem. 2001, 624, 5-17. http://dx.doi.org/10.1016/S0022-328X(00)00837-8

26. Ghorai, B. K.; Herndon, J. W.; Lam, Y. F. Org. Lett. 2001, 3, 3535-3538. http://dx.doi.org/10.1021/o10166404

27. Ghorai, B. K.; Menon, S.; Johnson, D. L.; Herndon, J. W. Org. Lett. 2002, 4, 2121-2124. http://dx.doi.org/10.1021/o1025808y

28. Woo, S.; Keay, B. A. Tetrahedron: Asymmetry 1994, 5, 1411-1414. http://dx.doi.org/10.1016/0957-4166(94)80098-7

29. Menon, S.; Sinha-Mahapatra, D.; Herndon, J. W. Tetrahedron 2007, 63, 8788-8793. http://dx.doi.org/10.1016/j.tet.2007.06.032

30. Trauner, D.; Bats, J. W.; Werner, A.; Mulzer, J. J. Org. Chem. 1998, 63, 5908-5918. http://dx.doi.org/10.1021/jo9805394

31. White, J. D.; Hrnciar, P.; Stappenbeck, F. J. Org. Chem. 1999, 64, 7871-7884. http://dx.doi.org/10.1021/jo990905z

32. Licandro, E.; Maiorama, S.; Vandoni, B.; Perdicchia, D.; Paravidino, P.; Baldoli, C. Synlett 2001, 757-760.

33. Alvarez, C.; Pacreau, A.; Parlier, A.; Rudler, H.; Daran, J. C. Organometallics 1987, 6, $1057-$ 1064. http://dx.doi.org/10.1021/om00148a025

34. Zhang, L.; Herndon, J. W. Tetrahedron Lett. 2002, 43, 4471-4473. http://dx.doi.org/10.1016/S0040-4039(02)00823-7

35. Camacho-Davila, A.; Gamage, L. S. R.; Wang, Z. P.; Herndon, J. W. Tetrahedron 2010, 66, 4954-4960.

http://dx.doi.org/10.1016/j.tet.2010.04.117

36. Herndon, J. W.; Patel, P. P. Tetrahedron Lett. 1997, 38, 59-62. http://dx.doi.org/10.1016/S0040-4039(96)02282-4

37. Suffness, M.; Douros, J. In Anticancer Agents Based on Natural Product Models; Cassady, J. M., Douros, J. D., Eds.; Academic Press: London, 1980; pp 465-487.

38. Kwon, Y.; Song, J.; Lee, H.; Kim, E. Y.; Lee, K.; Lee, S. K.; Kim, S. J. Med. Chem. 2015, 58, 7749-7762.

http://dx.doi.org/10.1021/acs.jmedchem.5b00764

39. Chang, Chi-Fen; Li, Chien-Fu; Tsai, Chia-Chen; Chuang, Ta-Hsien, Org. Lett. 2016, 18, 638641.

http://dx.doi.org/10.1021/acs.orglett.5b03395

40. Camacho-Davila, A.; Herndon, J. W. J. Org. Chem. 2006, 71, 6682-6685. http://dx.doi.org/10.1021/jo061053n

41. Banwell, M. G.; Bisset, B. D.; Busato, S.; Cowden, C. J.; Hockless, D. C. R.; Holman, J. W.; Read, R. W.; Wu, A. W. Chem. Commun. 1995, 2551-2553. 
http://dx.doi.org/10.1039/c39950002551

42. Iwao, M.; Mahalanabis, K. K.; Watanabe, M.; De Silva, S. O.; Snieckus, V. Tetrahedron 1983, 39, 1955-1962. http://dx.doi.org/10.1016/S0040-4020(01)91913-1

43. Ying, W. J.; Herndon, J. W. Eur. J. Org. Chem. 2013, 3112-3122. http://dx.doi.org/10.1002/ejoc.201300200

44. Ying, W. J.; Gamage, L. S. R.; Lovro, L. R., Herndon, J. W. III, Jenkins, N. W.; Herndon, J. W. Tetrahedron Lett. 2014, 55, 4541-4544. http://dx.doi.org/10.1016/j.tetlet.2014.06.056

45. Li, R. T.; Zhang, L.; Camacho-Davila, A.; Herndon, J. W. Tetrahedron Lett. 2005, 46, 5117 5120 .

http://dx.doi.org/10.1016/j.tetlet.2005.05.126

46. Patti, R. K.; Duan, S. F.; Wang, Z. P.; Herndon, J. W. Tetrahedron Lett. 2011, 52, 4182-4185. http://dx.doi.org/10.1016/j.tetlet.2011.06.006

47. Grotjahn, D. B.; Lev, D. A. J. Am. Chem. Soc. 2004, 126, 12232-12233. http://dx.doi.org/10.1021/ja046360u

48. Saha, M.; Muchmore, S.; van der Helm, D.; Nicholas, K. M. J. Org. Chem. 1986, 51, 19601966. http://dx.doi.org/10.1021/jo00361a004

49. Molander, G. A.; Jean-Gerard, L. J. Org. Chem. 2007, 72, 8422-8426. http://dx.doi.org/10.1021/jo7015955

50. Pezzella, A.; Lista, L.; Napolitano, A.; D'Ischia, M. Tetrahedron Lett. 2005, 46, 3541-3544. http://dx.doi.org/10.1016/j.tetlet.2005.03.060

51. Ghorai, B. K.; Herndon, J. W. Organometallics 2003, 22, 3951-3957. http://dx.doi.org/10.1021/om030383k.

52. Hoye, T. R.; Vyvyan, J. R. J. Org. Chem. 1995, 60, 4184-4195. http://dx.doi.org/10.1021/jo00118a040.

53. Gómez-Gallego, M.; Mancheño, M. J.; Sierra, M. A. Acc. Chem. Res. 2005, 38, 44-53. http://dx.doi.org/10.1021/ar040005r

54. Zhang, Y.; Herndon, J. W. J. Org. Chem. 2002, 67, 4177-4185. DOI: 10.1021/jo011136y.

55. Zhang, J.; Zhang, Y.; Schnatter, W. F. K.; Herndon, J. W. Organometallics 2006, 25, 12791284.

http://dx.doi.org/10.1021/om051008q

56. Barluenga, J.; Aznar, F.; Palomero, M. A.; Barluenga, S. Org. Lett. 1999, 1, 541-543. http://dx.doi.org/10.1021/o19906256

57. Waters, M. A.; Brandvold, T. A.; Isaacs, L.; Wulff, W. D.; Rheingold, A. L. Organometallics 1998, 17, 4298-4308.

http://dx.doi.org/10.1021/om980509r

58. Zhang, Y.; Herndon, J. W. Tetrahedron Lett. 2006, 47, 5303-5306. http://dx.doi.org/10.1016/j.tetlet.2006.05.127

59. Ghorai, B. K.; Duan. S.; Jiang, D.; Herndon, J. W. Synthesis 2006, 3661-3669. 


\section{http://dx.doi.org/10.1055/s-2006-950286}

60. Ghorai, B. K.; Jiang, D.; Herndon, J. W. Org. Lett. 2003, 5, 4261-4263. http://dx.doi.org/10.1021/o1035405d

61. Hohmann, F.; Siemoneit, S.; Nieger, M.; Kotila, S.; Dötz, K. H. Chem. Eur. J. 1997, 3, 853859. http://dx.doi.org/1002/chem.19970030605

62. Whitney, S. E.; Rickborn, B. J. Org. Chem. 1988, 53, 5595-5596. http://dx.doi.org/10.1021/jo00258a053

63. Patti, R. K.; Waynant, K. V.; Herndon, J. W. Org. Lett. 2011, 13, 2848-2851. http://dx.doi.org/10.1021/ol200825j

64. Söderberg, B. C.; Hegedus, L. S. Organometallics 1990, 9, 3113-3121. http://dx.doi.org/10.1021/om00162a024

65. Patti, R. K.; Duan, S.; Camacho-Davila, A.; Waynant, K.; Dunn, K. A.; Herndon, J. W. Tetrahedron Lett. 2010, 51, 3682-3684. http://dx.doi.org/10.1016/j.tetlet.2010.05.049

66. Luo, Y. M.; Herndon, J. W. Organometallics 2005, 24, 3099-3103. http://dx.doi.org/10.1021/om0502279

67. Roy, P.; Mitra, P.; Ghorai, B. K. Tetrahedron Lett. 2013, 54, 1440-1443. http://dx.doi.org/10.1016/j.tetlet.2013.01.005

68. Duan, S.; Kress, C.; Waynant, K.; Ramos-Miranda, E.; Herndon, J. W. Tetrahedron 2007, 63, 2959-2965.

http://dx.doi.org/10.1016/j.tet.2007.01.046

\section{Authors' Biographies}

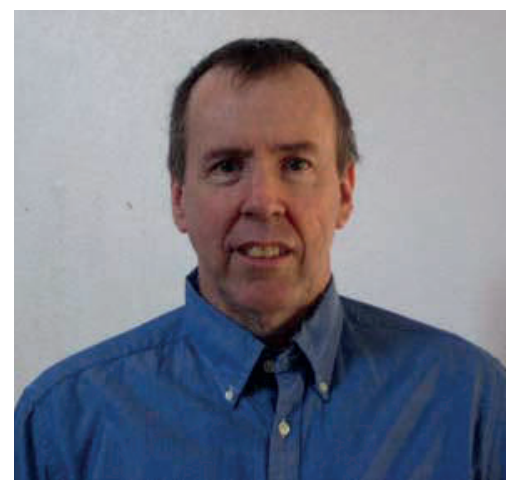

James W. Herndon was born and raised in North Carolina, USA, and attended college at a local institution, the University of North Carolina at Greensboro, as an undeclared major. After taking organic chemistry, the author was hooked and later was given the opportunity to participate in research in the laboratory of Prof. James Barborak working in the area of iron-catalyzed rearrangements of alkenes. From there he pursued doctoral work at Princeton University in the research group of Prof. Martin Semmelhack, where he worked on nucleophilic addition to iron- 
diene and arene-chromium complexes. These studies gave the author a fine appreciation of looking for the "accidental discovery" which is to this day a major way that he looks at research projects. After a postdoctoral appointment with Prof. Barry Trost at the University of Wisconsin at Madison in palladium and tin chemistry, where the author developed a deep appreciation for design efficiency and synthetic design, he began his independent career at the University of Maryland at College Park in 1985 with two primary goals, to develop acyliron complexes as carbene complex surrogates and to develop the "homo-Dötz reaction" where cyclopropylcarbene chromium complexes would substitute for $\alpha, \beta$-unsaturated carbene complexes and provide seven-membered rings instead of benzene rings. Both ideas failed early but fortunately yielded chemistry more interesting than the original plan. The author moved to New Mexico State University in 1997 and began pursuing primarily the chemistry described in this account coupled with some "accidental discoveries" that grew out of those investigations.

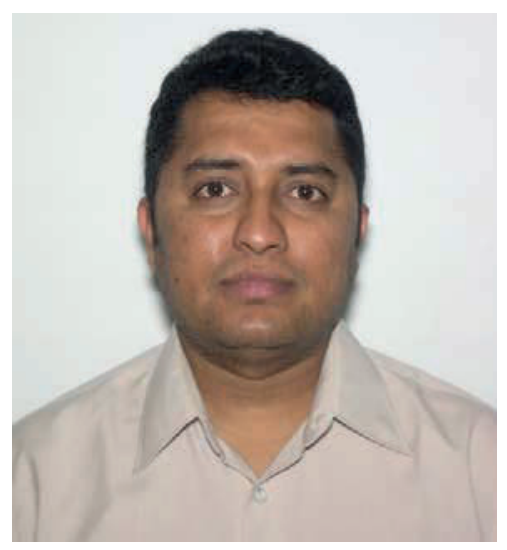

Bishnu Dhakal was born in 1981 in Nepal. He received B.Sc (in 2004) and M.Sc. (in 2007) degrees from Tribhuvan University Nepal. He taught chemistry for both high school students and undergraduates for few years in Nepal before coming to New Mexico State University as a graduate student in chemistry program. Currently he is working towards his $\mathrm{PhD}$ in chemistry under the supervision of Dr. James W. Herndon. His graduate research focuses on the reactions between Fischer carbene complexes with enynecarbonyl compounds to make polycyclic ring systems including synthesis of various biologically active molecules and natural products. Since August 2015 he started a position of chemistry instructor at National Park College, Arkansas, USA. 